\title{
Numerical Analysis of the Combustion Process in a Compressed Natural Gas Direct Injection Engine
}

\author{
Shahrir Abdullah, Wendy Hardyono Kurniawan and Azhari Shamsudeen \\ Department of Mechanical and Materials Engineering, National University of Malaysia, Bangi, \\ Selangor D.E., 43600 UKM Bangi, Malaysia \\ Email:shahrir@eng.ukm.my \\ (Received February 5, 2008; accepted February 25, 2008)
}

\begin{abstract}
The design, development and optimization of an internal combustion engine require the application of a modern sophisticated analysis tool. In addition to experimental work, numerical calculations are now necessary to provide an insight into the complex in-cylinder process. The combustion process and its emission characteristics in a compressed natural gas direct injection engine were analyzed and investigated. The numerical studies were performed on a single cylinder of a 1.6-liter engine running at wide open throttle. The grid generation was established through an embedded algorithm for moving mesh and boundary in order to provide a more accurate transient condition. The combustion process was modelled with the eddy break-up model of Magnussen for unpremixed or diffusion reaction with three global reaction scheme. The computational fluid dynamics (CFD) simulations at two baseline conditions are carried out to examine the fluid flow, air-fuel mixing formation, combustion process, carbon monoxide emission distribution as well as NO emission formation occurred inside engine cylinder. The CFD results were compared with the experimental data and showed a very good agreement for two baseline conditions. A set of parametric studies were carried out by varying the timings of start of injection (SOI) and start of ignition (SI). The examined engine performance is in-cylinder pressure, while the considered emissions to be minimised are $\mathrm{CO}$ and NO levels. In order to study the effect of injection timing, the SOI timing was varied from $120^{\circ}-140^{\circ}$ with fixed ignition timing at $19^{\circ} \mathrm{bTDC}$. On the other hand, SI timing was positioned from $15^{\circ}-23^{\circ}$ bTDC with fixed SOI timing for studying its influences. The CFD results indicated that slightly retarded SOI and SI timing can be chosen to reduce CO and NO levels while increasing engine performance.
\end{abstract}

Keywords: CFD; combustion; moving mesh; moving boundary; diffusion reaction; injection; ignition

NOMENCLATURE

$\begin{array}{ll}c_{v} & \text { heat capacity at constant volume } \\ \mathbf{g} & \text { gravitational acceleration } \\ k & \text { thermal conductivity coefficient } \\ p & \text { pressure } \\ S & \text { source term } \\ T & \text { temperature } \\ u & \text { velocity }\end{array}$

\section{INTRODUCTION}

Due to the growing concerns mentioned above about the harmful effects of conventional fossil fuel emissions have made natural gas a very attractive alternative fuel to internal combustion engine (ICE) due to its advantages to be environmental friendly, clean burning, economical and efficient fuel. For light-duty engine applications in particular, direct injection (DI) of compressed natural gas (CNG) promises thermal efficiencies comparable to those accomplished by high compression ratio, unthrottled diesel engines, while maintaining the smoke-free operation of spark ignition (SI) engines and producing slightly lower $\mathrm{NO}_{\mathrm{x}}$ emissions (Zeng et al. 2005). In view of meeting the more stringent emission regulations, there are still many technical difficulties to be resolved in

\section{Greeks}

$\Gamma \quad$ diffusivity coefficient

$\lambda$ bulk viscosity

$\mu \quad$ dynamic viscosity

$\rho$ density

$\sigma_{t} \quad$ turbulent Schmidt number

reducing simultaneously the emissions both $\mathrm{NO}$ and $\mathrm{CO}$ emitted from the internal combustion engine (Aslam et al. 2006). In recent years, CNG has been promoted as a promising clean fuel alternative to spark ignition engines because of its relatively higher octane level. Lean burning of $\mathrm{CNG}$ in $\mathrm{SI}$ engines has the potential to improve thermal efficiency and reduce emissions compared with the burning of gasoline. Due to its high research octane number ( $\mathrm{RON}>130), \mathrm{CNG}$ allows the combustion at higher compression ratio without knocking. It also offers much lower greenhouse gas emissions than those from the burning of other hydrocarbons as a result of its higher hydrogen to carbon ratio. Recently, the exact understanding of the physical and chemical processes is required to speed up the design 
process due to the increasing market demands of making new engines. The numerical computation by using CFD code are able to provide an improved insight into the complex in-cylinder processes due to its capability to solve the governing flow equations to produce detailed descriptions of the turbulent velocity fields and chemical reacting flows. Using multidimensional modelling, the phenomena occurring in ICE can be investigated and analysed, particularly with the rapid growth in high performance computing facilities, aiming to increase engine performance and reduce its emissions. Through the utilisation of multi-dimensional CFD code, the amount of manufacturing, testing, and data measurement can be diminished (Abdullah et al. 2005). In CFD modelling of ICE process, several processes, parameters and operating conditions are taken into account such as fuel injection, flame propagation, ignition model, chemical kinetic reaction, exhaust emission formations, knock tendency as well as the air-fuel ratio control. Therefore, while applying to the internal combustion process, CFD models have to address specific problems related the turbulent flow, high Reynolds number involved, and variable geometry of the solid boundaries. In consequence, computing times are highly costly and require huge computer memory as well as high performance computing (HPC) setup.

Based on the literature, many researchers recently have been working on natural gas-fuelled engines worldwide via experimental work or through numerical simulation. Shiga et al. (2002) have determined the characteristics of emissions from compressed natural gas $(\mathrm{CNG})$ directinjection combustion using experiment on a rapidcompression-machine having a compression ratio of 10 and a disc-shaped combustion chamber. Numerical studies have also been carried out mostly using the CFD code by Zhang and Frankel (1998) under the lean combustion and limited CFD analyses were carried out. Kusaka et al. (2000) for their investigation in dual fuel engine for both diesel and natural gas engine. Ando et al. (2003) has carried out CFD analysis of combustion processes with self-ignited natural gas engine. Lastly, Zheng et al. (2005) studied combustion process and fluid flow in a compression ignition natural gas engine with separated chamber using the CFD code. Up to date, multi-dimensional CFD modelling of a direct injected natural gas engine with spark ignition together with moving boundaries due to valves and piston movement has not been performed.

Therefore, the objective of this study was to analyse the combustion process for the $\mathrm{CNG}$ direct injection engine by utilising a CFD code and to compare against the available experimental data on a single cylinder research engine (SCRE) test bed. The combustion model used was the eddy break-up model which is suitable for the gaseous fuel. The engine model employed was the modified 1.6-liter Proton Campro engine retrofitted with direct fuel injected located at the central axis of the cylinder. The parametric studies were performed by varying the timings of SOI and SI to study the combustion behaviour of such engine. The effect of these two important parameters to the engine performance in the terms of in-cylinder pressure and emissions was investigated in details.

\section{ENGINE MODEL AND GRID GENERATION}

A single cylinder engine which is based on the 1.6 liter Proton Campro engine was modified into a CNG-fuelled engine with direct injection system. The engine was operated at wide open throttle condition and the compression ratio was kept at 10:1. The main engine specifications are given in Table 1 and the section view of the geometrical details can be depicted in Fig. 1 which shows the position of the intake and exhaust ports and valves, CNG injector, spark plug and combustion chamber.

CFD simulation of the combustion process was performed by using a moving mesh-boundary algorithm where its source code was developed and incorporated as user subroutine to the base CFD code. In developing the moving mesh and boundary algorithms, every event which is a function of crank angle represents different configurations of mesh and boundary geometries for an engine cycle. Hence, in order to perform a proper CFD simulations for an internal combustion process, the analysis and calculation should be carried out by using unsteady or transient calculation, moving mesh and boundaries, highly compressible, high Reynolds number, high turbulence intensity and chemical-reactive.

The grid generation starts from retrieving the mesh surface of the engine in form of CAD data as illustrated in Fig. 2. Then, this surface data is converted into finite volume mesh. In the present study, a grid generator program has been employed to create the hexahedral cells for the computational mesh for CFD calculation of the engine model, which involves the intake ports and valves, the cylinder head and the piston bowl as shown in Fig. 3a. The different colour shown here represents the parallel computation carried out in this study as four parallel computation process used. The number of cells ranges from 90,000 cells in TDC and around 180,000 200,000 cells in BDC, where about the half of the cells used to generate the mesh at the cylinder head and piston bowl. The fine grid arrangement is necessary during the valve movement to obtain the stability and convergence criteria. The hexahedral cells were used for the mesh generation due to better accuracy and stability compared to the tetrahedral cells. In addition, utilising the hexahedral cells was preferred when dealing with moving meshes and boundaries.

The computational domain is divided into four areas with different topologies due to its complexity, where each area has been meshed separately as shown in the wire frame view (Fig. 3b). This approach was used to obtain a good quality grid (mesh) and to reduce for meshing time significantly. The connectivity of the various subdomains is maintained by means of arbitrary interfaces that connect every faces of the zones. The mesh for both intake ports have been created using a similar topology, where the cell are oriented in the flow direction and joined with a cylindrical structured mesh in the zone upstream of the valves. The grid above the valves both intake and exhaust was constructed by the revolution of a structure mesh section. During the compression stroke, when the intake valves are closed, the sub-domains of intake ports are already disconnected from the calculation to reduce the computational time and cost. 


\section{NUMERICAL METHODOLOGY}

The numerical simulations were carried out based on a commercial CFD code with a couple of user subroutines added on to model moving mesh and boundary capability in order to replicate the real engine operating conditions, such as the valves and piston movement. In addition, a user subroutine written in Fortran code was also used to simulate direct fuel injection. In this section, the chemistry model and reaction mechanism utilized for the CFD calculation of the combustion process are described here together with the initial and boundary conditions performed.

\subsection{Governing Equations}

The governing equations for the gas flow and the combustion process can be described as: Mass equation:

$$
\frac{\partial \rho}{\partial t}+\nabla \cdot(\rho \mathbf{u})=0
$$

Momentum equation:

$$
\begin{aligned}
& \rho \frac{\partial \mathrm{u}}{\partial t}+\rho(\mathrm{u} \cdot \nabla) \mathrm{u}=-\nabla p+ \\
& \nabla \cdot\left\{\mu[\nabla \mathrm{u}+(\nabla \mathrm{u})]^{\mathrm{T}}+\lambda(\nabla \cdot \mathrm{u})\right\}+\rho \mathrm{g}
\end{aligned}
$$

Energy equation:

$$
\begin{aligned}
& \rho c_{v} \frac{\partial T}{\partial t}+\rho c_{v}(\mathrm{u} \cdot \nabla) T=-p(\nabla \cdot \mathrm{u})+\nabla(k \nabla T)+ \\
& \lambda(\nabla \cdot \mathrm{u})^{2}+\nabla \mathrm{u} \cdot\left\{\mu\left[\nabla \mathrm{u}+(\nabla \mathrm{u})^{\mathrm{T}}\right]\right\}
\end{aligned}
$$

The turbulence model employed was the $k-\varepsilon$ turbulence model (El-Tahry 1983) for the compressible flow and high Reynolds number.

\subsection{Solution Algorithms}

As mentioned previously, a CFD code of finite volume method has been used to solve the discretised partial differential equations governing the mean fluid motion, which is based on the pressure-correction method. The discretisation of space in the appearance of cell numbers and time in the form of time stepping are set after the Courant number, which provide a reliable indication of the suitability of the discretisation settings. The time discretisation is necessary to obtain the best compromise between the convergence requirements and the computing time i.e. the smaller time steps were set for initiating simulations and when the crank angle reached the fuel injection timing and the TDC position.

For each case, the time steps were defined as $0.83 \mu$ s for case A and $2.78 \mu$ s for case B, respectively. The temporal discretisation is implicit with the under relaxation factors of 0.1 to accomplish the criterion of unconditional numerical stability, while the accurate second order differencing scheme of MARS (monotone advection and reconstruction scheme) was employed for the momentum, energy and turbulence equations together with the arbitrary Lagrangian Eulerian (ALE) technique for the grid movement associated with moving piston and valves. The PISO algorithm for unsteady flows is then chosen to solve the problem.
To ensure the accuracy and stability of the CFD simulation, the Courant number of engine model needs to be monitored so that the execution process can lead to convergence. From the generated residual file, there are cells inside the computational model with the highest Courant number, which is 1.8. The highest Courant number should be monitored carefully to avoid divergence and instability.

\subsection{Combustion Model}

The type of chemical reaction model used to simulate the combustion process of compressed natural gas was unpremixed or diffusion reaction. The background of using the diffusion reaction for such engine modelling is due to the mono-fuel (methane) operation. In this reaction, the fuel and oxidant (air) streams enter the engine cylinder as the solution domain separately. For modelling, it is necessary to solve one additional differential conservation equation for each reaction considered. The chosen scalar is known as the mixture fraction, $\phi$, and is defined as the total mass fraction of burned and unburnt fuel. The scalar $\phi$ is obtained by solving the following equation in vector notation:

$$
\frac{\partial}{\partial t}(\rho \phi)+\nabla \cdot(\rho \mathrm{u} \phi)=\nabla \cdot\left(\rho \Gamma+\frac{\mu_{t}}{\sigma_{\phi, t}}\right) \frac{\partial \phi}{\partial x_{j}}
$$

For the simulation of the turbulent combustion, the eddy break-up model of Magnussen (Magnussen 1981) was implemented in the present study. The EBU model was usually developed for any combustion applications and is based on the two assumptions since the reaction is a single-step irreversible one involving fuel $(F)$, oxidant $(O)$ and products $(P)$, plus possible background inert species and the reaction time scale is so small that the rate-controlling mechanism is turbulent micromixing. According to the employed model, the fuel consumption rate is mentioned as follows:

$$
\begin{aligned}
& R_{F}=-\frac{\rho \varepsilon}{k} A_{e b u} \min \left[Y_{F}, \frac{Y_{O}}{s_{O}}, B_{e b u} \frac{Y_{P}}{s_{P}}\right] \mathrm{kg} / \mathrm{m}^{3} \mathrm{~s} \\
& s_{O} \equiv \frac{n_{O} M_{O}}{n_{F} M_{F}} \text { and } s_{O} \equiv \frac{n_{O} M_{O}}{n_{F} M_{F}}
\end{aligned}
$$

where $A_{e b u}$ and $B_{e b u}$ are the dimensionless empirical coefficients with nominal modified values for higher RON as 12 and 0.8 , respectively, according to the burned mass fraction of fuel during combustion. In Eq. 5, $k$ is the turbulence kinetic energy, $\varepsilon$ is the turbulence dissipation rate and $Y$ is the mass concentration for fuel $(F)$, oxidant $(O)$ and products $(P)$. In Eq. 6, $s$ is defined as the mass fraction, $n$ is the number of molecul and $N$ is the molar concentration for fuel $(F)$, oxidant $(O)$ and products $(P)$. The first two arguments in the square brackets of that equation determine the local rate-controlling mass fraction, while the third is intended to inhibit reaction where the temperature is low and can be omitted. The micromixing time scale is taken to be $k / \varepsilon$, the dissipation time scale.

\subsection{Reaction Mechanism}

The combustion modelling strategy occupied to the CFD model was based on the three-step global reaction of EBU model as mentioned previously. The three-step 
global reaction of EBU applied in this study is as follows:

$$
\begin{aligned}
\mathrm{CH}_{4}+0.5 \mathrm{O}_{2} & \rightarrow \mathrm{CO}+2 \mathrm{H}_{2} \\
\mathrm{CO}+0.5 \mathrm{O}_{2} & \rightarrow \mathrm{CO}_{2} \\
\mathrm{H}_{2}+0.5 \mathrm{O}_{2} & \rightarrow \mathrm{H}_{2} \mathrm{O}
\end{aligned}
$$

The mixture was assumed to obey the ideal gas law. The viscosity, the thermal conductivity and the specific heat of the mixture are computed from the properties of individual species, and these are all functions of temperature. The mass fractions of the combustion products were assumed to follow the local and instantaneous thermodynamic equilibrium values. The equilibrium composition of the cylinder charge was dependent on the pressure, temperature and equivalence ratio (Olikara and Borman 1975). The considered chemical species for the CFD calculation were $\mathrm{O}_{2}, \mathrm{CO}_{2}$, $\mathrm{H}_{2} \mathrm{O}, \mathrm{N}_{2}, \mathrm{H}_{2}, \mathrm{CO}$ and $\mathrm{NO}$ whereby natural gas is considered as $100 \%$ methane $\left(\mathrm{CH}_{4}\right)$.

\subsection{Fuel Injection Modelling}

For the modelling of the fuel injection process into engine cylinder, the inlet boundary in the hole injector of the CFD model are introduced where the fuel injection velocity can be applied into the computational meshes (Agarwal and Assanis 2000). The specification of the mass flow rate of injector is $0.6122 \mathrm{~g} / \mathrm{s}$ for low pressure injector and $1.3233 \mathrm{~g} / \mathrm{s}$ for high pressure injector, respectively, which was calculated from the injection pressure taken from the experiment. These conditions produced the injection velocity defined for inlet boundary as $39.78 \mathrm{~m} / \mathrm{s}$ and $64.22 \mathrm{~m} / \mathrm{s}$, respectively.

\subsection{Ignition Modelling}

CFD simulation can be used as a numerical tool to detect start of combustion process by examining the beginning of spark ignition event. An accurate description of the early stage of ignition is very important to model the initiation of the combustion process successfully. In order to model ignition process, the ignition cells around 3-5 mm are introduced within the computational domain to start the combustion process artificially.

For the purpose of ignition modelling, it is necessary to initiate the specified chemical reaction by specifying an ignition mechanics. In the present study, the ignition modelling is performed by reducing the fuel mass fraction to 0.0505 in the ignition region of the solution domain. This reduced fuel mass fraction provides the signals to inform that a small proportion of the fuel has already been burned and is therefore necessary to start the combustion simulation process. The ignition cells ere located near the spark plug as depicted in Fig. 4.

\subsection{Fuel Properties}

Natural gas is a mixture of lower hydrocarbon gases and consists mainly of methane with small percentages of higher alkenes, such as ethane and propane, and possible small fraction of incombustible products such as nitrogen and carbon dioxide. For an ideal simulation, the composition of CNG utilised in the present study was assumed to be $100 \%$ methane $\left(\mathrm{CH}_{4}\right)$. Such consideration is quite reasonable due to the fact that the Malaysian CNG contains mostly of methane as almost reaches $98 \%$
(Aslam et al. 2006). The generation of higher in-cylinder pressure is determined by the main hydrocarbon fuel contained in the chemical reaction, and the emissions formation of $\mathrm{CO}$ and $\mathrm{NO}$ are highly controlled by the amount of residual fuels due to the oxidation and the quantity of air within cylinder.

\subsection{Simulated Engine Operating Conditions}

The engine operating conditions chosen for the CFD simulation with the purpose of comparing it against the experimental data are dedicated for both low and high engine speeds i.e. 2000 and $6000 \mathrm{rpm}$, respectively. The engine operating conditions consider certain variations in the intake temperature, injection timing, injection duration and spark ignition timing as listed in Table 2.

\subsection{Initial and Boundary Conditions}

The calculations were started at the crank angle degrees of $140^{\circ}$ before TDC for case A and $220^{\circ}$ before TDC for case B, respectively and finished at $40^{\circ}$ after TDC, which covers the compression stroke, fuel injection process and combustion process. The initial pressure and temperature within engine cylinder need to be defined to provide the initial conditions of governing equations to be solved. The initial pressure was positioned at 1.05 bar and 0.90 bar for case A and B, respectively. The initial temperature of $293 \mathrm{~K}$ and $288 \mathrm{~K}$ was set for case A and $\mathrm{B}$, respectively too. The time step used for every degree of crank angles for three mentioned processes is 0.1 , which means that ten time steps will be needed to calculate one degree of crank angle. The reason of choosing the smaller time steps is to avoid the negative densities occurred during the calculation, especially when the mesh distort during the intake and exhaust opens and closes, respectively and capture the detail of the pressure alterations during the combustion process. Initially, the gas in the computational domain is assumed to be quiescent and its temperature and pressure are assumed to be homogeneous condition and at the atmospheric condition, respectively. The computational gas is assumed to be the fresh air. The initial value of the turbulent kinetic energy $k$ is assumed to be spatially uniform and is set equal to $3 \%$ of the kinetic energy of the mean piston speed. The boundary conditions at the intake and exhaust ports are the pressure boundaries. The pressure and temperature at the intake port are positioned to $100 \mathrm{kPa}$ and $305 \mathrm{~K}$, respectively. On the other hand, the pressure at the exhaust port need to be kept constant at atmospheric condition and the temperature predicted from the measurement result is defined as $802 \mathrm{~K}$. The calculations were executed by using the HPC facility of a SGI Origin 300 server - 4 CPU with 145 MByte memory used and cost about 25 hours and 32 hours of CPU time for cases A and B, respectively. The details of the boundary conditions implemented into the engine model are displayed in Fig. 5, which depicts the boundaries of the adiabatic pressure, fuel inlet for injection, cylinder walls, upper and lower valve walls as well as the cylinder attachment for the mesh movement of cylinder mesh during engine cycle.

\subsection{Emission Modelling}

For the emission modelling, its concentration was modelled using the dissociation of carbon dioxide and three extended Zeldovich mechanisms for the calculation of CO and NO, respectively (Pulkrabek 2004). CO is 
usually generated in an engine when it is operated with a fuel-rich equivalence ratio. When there is not enough oxygen to convert all carbon to $\mathrm{CO}_{2}$, some fuel portions do not get burned and some will produce CO. Normally the exhaust of a spark ignition engine contains about $0.2 \%$ to $5 \% \mathrm{CO}$. The $\mathrm{CO}$ emission was modelled by following the mass equilibrium law in which the total mass fraction of each species involved in the chemical reaction was maintained as equal for each time steps.

As for $\mathrm{NO}_{x}$, it was generated throughout the combustion chamber during the combustion process due to the reaction between oxygen and nitrogen atoms. The forming of $\mathrm{NO}_{x}$ is very temperature dependent, where $\mathrm{NO}_{x}$ emission is relatively low during engine start and warm-up and is beginning to form when the high temperature burned gases is left behind by the flame front. The following three chemical equations that form the extended Zeldovich reaction and known as thermal NO can be mentioned as below:

$$
\begin{aligned}
& \mathrm{O}+\mathrm{N}_{2} \rightarrow \mathrm{NO}+\mathrm{N} \\
& \mathrm{N}+\mathrm{O}_{2} \rightarrow \mathrm{NO}+\mathrm{O} \\
& \mathrm{N}+\mathrm{OH} \rightarrow \mathrm{NO}+\mathrm{H}
\end{aligned}
$$

\subsection{Grid Dependency}

A grid dependency test for the engine computational mesh has been performed for the purpose of checking the finer mesh configuration employed in this paper. The refined mesh has the more quarter number of cells (Fig. 6b) as in the second case than the current mesh configuration (Fig. 6a) as in the first case. On the other hand, the third case is the mesh configuration with half finer mesh (Fig. 6c) than the first case. The grid independence study performed has proved that the quarter and half finer mesh does not influence to the solved numerical parameters, such as cylinder pressure and temperature as shown in Figs. 7 and 8, respectively. Similar patterns can also be observed for other parameters, such as swirl ratio, tumble ratio, turbulence velocity field, and certain concentration of combustion species. As can be seen in Figs. 6 and 7, there are no significant differences between the CFD solutions obtained between the three compression calculations. However, the CPU costs are nearly tripled in the case of the refined computational mesh and it does not give the advantages to the CFD calculation. Therefore, it can be summarised that the current normal mesh is sufficient to obtain the numerical stability and accuracy for the present in-cylinder flow analysis.

\section{CALCUlation RESUlts OF BASELINE CONDITION}

The calculation result of the baseline condition displayed here was executed based on the case A for the model having the engine operating condition as outlined in Table 2. The main objective of presenting the baseline calculations is to investigate and determine some phenomena occurring in the mixture formation and combustion process, such as the in-cylinder air motion during intake stroke, spray formation during fuel injection, in-cylinder air-fuel mixing, the event of spark ignition timing, in-cylinder pressure and temperature distribution, pattern of fuel mass burned, $\mathrm{CO}$ emission formation as well as its $\mathrm{NO}$ emission composition.

\subsection{In-cylinder Air Motion}

Figure 9 shows the velocity fields at the time of maximum intake valves lift for different section view. It can be seen that there are strong annular jet flows in the area near the valve curtains because the flow and velocity field in this event reaches its maximum value where the intake valves almost open at the maximum lift distance. Such strong annular jet flows make a clockwise swirl on the one intake valve and a counter-clockwise on another intake valve as shown clearly in Fig. 9(a). During this period, the piston speed is nearly constant and the intake valves are almost fully open (maximum lift). The developed toroidal vortex in the early part of the intake stroke has already disappeared due to stronger velocity field vectors. Nevertheless, a new clockwise vortex exists as can be seen in Fig. 9(b) located in the centre of the engine cylinder, especially under intake valves as a result of the jet motion towards the central part of the cylinder, which does not collide directly with the cylinder walls. This annular jet flows that impinges on the wall is deflected axially towards the piston with centre bowl and produces an elongated vortex along the wall. In addition, Fig. 9(c) confirms that there are several vortices exist with no predominant pattern and that the flow field is symmetric with respect to a vertical plane situated between the two intake valves.

The other in-cylinder feature characteristic is the unsymmetrical structure of the in-cylinder flow (Fig. 10). In this figure, the instantaneous streamlines at $108^{\circ}$ after TDC, represented by continuous lines, are presented. There are some streamlines illustrated to show the path of the air-low inside the combustion chamber. It can be seen that swirl is present and is generated at some location of cylinder wall during intake stroke. The flows are seen relatively symmetrical about the centre plane between two valves due to the symmetrical runner, port and valve configuration. This symmetrical flow structure and pattern implies that the bulk flows from the two valve openings do not mix together significantly.

\subsection{Direct Fuel Injection}

The fuel injection, which occurs inside cylinder, can be investigated to obtain the behaviour of the fuel injected into combustion chamber. The start of the fuel injection (SOI) is $230^{\circ} \mathrm{CA}$ and the injection duration is $50^{\circ} \mathrm{CA}$. The equivalence ratio is necessary to be kept under the stoichiometric condition. Figure 11 shows the streamlines of spray pattern for each degree of crank angles during the fuel injection process to characterize the dynamic behaviour of the spray formation. Unlike gasoline fuel, there is no droplet and evaporation generated during injection process due to its physical properties as the gaseous fuel. As can be figured out, the behaviour of CNG fuel injected goes downward and produces certain spray angle i.e. 70 degree from the detection of spray pattern. At the time of $240^{\circ} \mathrm{CA}$, which is $10^{\circ} \mathrm{CA}$ after fuel injection begins, the spray formation creates some swirl structures within cylinder as required to be mix with the air. During the late part of the fuel injection process, the fuel within combustion chamber nearly touches the top surface of piston before it is compressed until the spark ignition starts. 
In performing direct fuel injection, customization is required when introducing direct injection algorithm in the simulation since this facility has to be done via programming using the user subroutine. The injection timing should be synchronized with the engine timing. In this case, the authors have verified this code using the eddy break-up (EBU) model provided in the CFD software. This verification is essential in order to prove that the developed user subroutine for direct injection of such natural gas engine work properly for every time step according to the right engine timing.

Figure 12 shows the amount of methane injected into combustion chamber as a function of crank angle in milligram (mg). Methane is injected in a slug profile from $230^{\circ} \mathrm{CA}$ to $280^{\circ} \mathrm{CA}$, which the amount of methane attains around $5.2 \mathrm{mg}$ at the end of fuel injection. After fuel injection finished, there is no methane injected so that the profile is constant during the rest part of compression stroke and early part of expansion stroke. This observation can represent the profile of injected methane versus crank angle during injection duration which follows the linear relationship due to the fixed mass flow rate defined in the inlet boundary of hole injector.

\subsection{In-cylinder Mixture Formation}

Figure 13 shows the sequence period of $\mathrm{CNG}$ injected into the engine cylinder during the fuel injection process in the plotted form of crank angle position. As noticed from the simulation, the fuel goes down with its certain velocity to mix with air during compression stroke to provide the stoichiometric condition required for $\mathrm{CNG}$ to be burned before spark ignition timing. The physical phenomenon able to be captured from the computational study is that the contour plot of fuel mixture will reach the steady condition at the later part of injection process even though the crank angle was still changing to compress the air-fuel mixture for the ignition burning. The other important thing can be observed here is that the behaviour of injected fuel when dropping down can be captured well by the piston crown shape in the middle of cylinder. Such circumstance is required to provide the homogeneous mixture for the rapid combustion process so that CNG as a mono-fuel can be burned completely along cylinder wall. At the end of fuel injection process, the fuel within combustion chamber has touched the top surface of piston before it is compressed upwards

The mixture distribution of fuel and air inside cylinder in milligram (mg) as a function of crank angle can be observed as shown in Fig. 14, where the relationship of the air-fuel mixture along the degree of crank angle is almost relatively linear at the event of fuel injection and at the time of combustion process. The mixture distribution contains around $5.2 \mathrm{mg}$ after the fuel injection is finished. After combustion starts, it increases until it reaches around $16 \mathrm{mg}$, since the fuel is being continuously burned during expansion stroke. From this point of view, the combined chemical reactions between fuel and air, particularly, oxygen and nitrogen provide the stoichiometric condition required for complete combustion.

\subsection{Spark Ignition}

The temperature contours of engine cylinder that shows the propagation of the burning mean flame front can be depicted in Fig. 15. By detecting the result of CFD calculation, the spark timing takes place initially at the crank angle position of $341^{\circ} \mathrm{CA}$ as has been setup and the temperature changes dramatically at $348^{\circ} \mathrm{CA}$ as can be seen from the temperature contour at the region near spark plug. Such clear transformation of temperature value is a sign of combustion that is already started inside the engine cylinder. The ignition delay as the period between the spark timing and start of combustion in this study that can be detected from CFD study is $7^{\circ} \mathrm{CA}$. As noticed, the mean flame front propagates relatively slow in the vicinity of cylinder wall, as it should. This physical behaviour is due to the fact that the turbulence time scale becomes small near the cylinder wall and results in relatively high flame propagation rates.

\subsection{Flame Propagation}

The propagation and structure of the flame can be figured out in Fig. 16 as a function of temperature, in which the progress variable is plotted in form of cross section through the cylinder centreline several crank angle positions to demonstrate the temperature increment inside cylinder because of the action from spark plug to kick-off the combustion process. The unburned regions are indicated by bright colour while the burned regions are illustrated by dark colour. The two intake valves are shown in order to view the section outlook for a spark plug position. Shortly after ignition the originally spherical flame kernel shows a preferential burn direction. From observation, it can be concluded that the flame propagates much faster to the direction where the spark plug is located. Therefore, the flame reaches the squish region on the side of spark plug location within combustion chamber several degrees of crank angle earlier than the squish region on the other part of engine cylinder.

The explanation for this behaviour is that the turbulence kinetic energy as a small scale motion plays an important role on the effect of the turbulent propagating flame and thus the reaction rate of fuel burning. Figure 17 illustrates a heterogeneous of turbulence intensity distribution during the compression stroke as influencing the structure of flame propagation. In the region of the intake valves, the high turbulence kinetic energy of $23 \mathrm{~m}^{2} / \mathrm{s}^{2}$ can be observed from CFD calculation. On the other side, its values are relatively smaller in the region of the exhaust valves.

In order to investigate the flame propagation on the bottom part of piston, Fig. 18 is presented to examine the trend of flame burning during expansion stroke. As can be captured, the fuel burned with random distribution along the surface of the piston before expanding to the whole surface of cylinder after the combustion is nearly completed. The physical condition from CFD calculation of combustion process in this study is that the fuel rich mixtures is produced along the surface of the piston and leaner mixtures is generated towards the cylinder head. Based on the combustion theory, the reaction rates and temperature are the highest at the location near the stoichiometric mixtures, which is in the middle of the combustion chamber. By the nature of EBU model of combustion utilized, the local rate of burning is highest in the regions that have low turbulence time scale rate and fuel-air mixtures, which is closed to the stoichiometric proportions. 
The mass fraction burned curve, shown in Fig. 19, depicts the S-shaped curve profile, which is the common characteristic of combustion process in both sparkignition and diesel engines. By comparing with the gasoline fuel, the burning rate of $\mathrm{CNG}$ is relatively faster due to its high octane number resulting in a fast flame speed (Pulkrabek 2004). At $20^{\circ} \mathrm{CA}$ after TDC, the fuel has been burned around $80 \%$. It also can be seen that not all the injected fuel burns during the combustion process, which will cause the formation of $\mathrm{CO}$ emission.

In Fig. 20, the effective fuel injection rate curve in $\mathrm{mg} / \mathrm{deg}$ can be plotted as a function of crank angle. The area under the curve is approximately equal to the actual mass of fuel exists inside the combustion chamber. As can be pointed out, the maximum rate of burning takes place around $10^{\circ} \mathrm{CA}$ before TDC, where the fuel is consumed rapidly after the ignition delay period is over. After that, the apparent of burning rate decreases gradually because the combustion process has taken over so that the methane is not consumed any longer. The process occurred during the power stroke, in which the piston is kicked downward to produce the engine power. The deterioration of the methane burning rate continues until around $30^{\circ} \mathrm{CA}$ after TDC.

\subsection{In-cylinder Pressure and Temperature}

The contour plot of in-cylinder pressure during the combustion process to characterise the behaviour of combustion pressure for certain crank angle positions can be seen in Fig. 21 which shows the expansion stroke from the TDC position. As can be predicted, the pressure will reach its maximum value at the top part of the cylinder head when the piston reaches the TDC position during the compression stroke. It also can be noticed that the peak pressure tend to appear in the side part of engine cylinder, which is near to the spark plug position. This phenomenon reveals that the burned fuel causes the movement of flame propagation to the side part of engine cylinder near the spark plug instead of distributing uniformly.

The temperature increment inside cylinder during the combustion process can be shown in Fig. 22. The red region in illustration represents a highest temperature around $3400 \mathrm{~K}$ to show the burned mixture in certain locations within engine cylinder. The phenomenon of the combustion temperature is relatively distributed symmetrically between the side of intake and exhaust valves which proves that the piston is able to move downward smoothly during the expansion stroke.

Figure 23 shows the variation of the mass-averaged incylinder combustion pressure and temperature versus crank angle for the baseline condition. It indicates that the in-cylinder pressure and temperature increase rapidly around $340^{\circ} \mathrm{CA}$, where the spark ignition begins. The maximum pressure and peak temperature occurs within engine cylinder is around $3.58 \mathrm{MPa}$ and $1450 \mathrm{~K}$, respectively. The maximum pressure takes place at the crank angle around $375^{\circ} \mathrm{CA}$ while the peak temperature arises around $390^{\circ} \mathrm{CA}$ and both is occurring during the expansion stroke to move piston downwards.

\subsection{Heat Release Rate}

The heat release rate is defined as the rate at which the chemical energy of the fuel is released by the combustion process. It is calculated from cylinder pressure versus crank angle as the energy release required creating the measure pressure. From the simulation results, the rate of heat release is directly extracted from the reactive species and their heat formation. By evaluating the heat release rate produced from the engine, the combustion duration can be predicted to maximize the work done when piston reaches the constant volume stage at the BDC position. Based on the theory of combustion, the combustion depends on the equivalence ratio, residual fraction, spark timing, laminar flame speed, turbulence intensity of flow and combustion chamber shape (Fergusson and Kirkpatrick 2001).

In Fig. 24, the heat release rate generated during the combustion process can be shown in $\mathrm{J} / \mathrm{deg}$. As expected in a spark ignition engine, the single peak shape of the heat release profile observed at the same crank angle producing peak pressure. The peak value of around 80 $\mathrm{J} /$ deg occurs during the unpremixed combustion phase which is as result of the rapid combustion of the portion of the injected fuel that has mixed with the air during the ignition delay period. The heat release rate during this phase is also influenced by the injected duration. As the injection duration is increased, the amount of fuel injected increases, thus increasing the magnitude and duration of the mixing controlled heat release. After reaching the maximum value, the heat release decreases during the expansion stroke with random fluctuations due to the incomplete combustion. This is due to the residual fuel burns at certain region around engine cylinder where the partial combustion occurs and hence deteriorates the combustion efficiency.

\subsection{Emission Formation of $\mathrm{CO}$ and NO}

From CFD simulation, the emission concentration of $\mathrm{CO}$ and NO within engine cylinder due to the combustion process can be predicted and determined. Figures 25 and 26 present the concentration of $\mathrm{CO}$ and $\mathrm{NO}$, respectively, occurred in the middle of cylinder for several crank angles during and after the combustion. It can be seen that most of the $\mathrm{CO}$ concentration is located next to the cylinder liner wall and inside the piston bowl. It is a result of poor combustion as a result of the oxidation process from $\mathrm{CO}$ to $\mathrm{CO}_{2}$ in the core gas and due to the wall quenching. Carbon monoxide is an intermediate combustion product and it is present in low concentration in the region where combustion does not take place at all.

On the other hand, the majority of the NO formation resides in the region around spark plug and it is the result of higher temperature produced during spark ignition timing. Nitrogen oxide is a species generated within the combustion chamber during combustion because of the reaction of $\mathrm{O}$ and $\mathrm{N}$ atoms and it is exists in the region where the higher temperature situated. In addition to temperature, the amount of NO generated depends on the pressure, air-fuel ratio and combustion time within the cylinder. It also depends on the location within the combustion chamber. The highest concentration is formed around the spark plug, where the highest temperature arises as shown here.

The global variations of $\mathrm{CO}$ and $\mathrm{NO}$ emission concentration produced from the combustion process can be studied in Figs. 27 and 28, respectively as the function of degree crank angle. As can be seen, the CO species initially occurs at $8^{\circ} \mathrm{CA}$ before TDC due to ignition timing and reaches its maximum value at $20^{\circ} \mathrm{CA}$ after 
TDC. This condition is due to insufficient of carbon dioxide $\left(\mathrm{CO}_{2}\right)$ required to convert the fuel to oxygen during the combustion. On the other hand, the NO species also appeared at $8^{\circ} \mathrm{CA}$ before TDC before reaching its maximum amount at $30^{\circ} \mathrm{CA}$ after TDC, when cylinder temperatures are very high. After that, the NO emission will decrease a little bit before keeping its concentration for the remaining crank angle until the beginning of the exhaust stroke. The critical time period for NO formation has been shown to be when the burned gas temperatures are at a maximum value, which is between the start of combustion and shortly after peak cylinder pressure has occurred. Mixture that burns early in the combustion process are important as it is compressed to a higher temperature, resulting in the increment of NO formation rate. This condition if combined with the mixing of high temperature gases with air or cooler burned gas will contain the $\mathrm{NO}$ and its concentration remains essentially constant during the late expansion stroke. The constant value of NO concentration during expansion and exhaust stroke does not presented here due to the limitation of the defined time step calculations in this study. Although there is no available data for the prediction of exhaust emission as part of this study, the values obtained lie in the general range for any spark ignition engine (Heywood 1988). In any event, our interest is primarily focused on their relative values as the engine operating parameters are changed.

The results of the baseline calculation have shown that the prediction methodology of the ignition, combustion and pollutant formation used in this work provides physical meaning in order to understand the real physical condition occurring in the engine with methane as a mono-fuel operated in a spark ignition engine. In the following sections, the comparison of CFD result and the available experimental data are presented to assess the accuracy of the CFD and combustion model employed.

\section{EXPERIMENTAL COMPARISON}

\subsection{Experimental Setup}

The experimental setup for the purpose of comparing the CFD simulation was carried out in a SCRE test rig as shown in Fig. 29. The available data used for the numerical comparison was performed by considering some important technical aspects. During the experiment, all engine boundary conditions were fixed. Piezoelectric pressure sensors (Kistler 6061B) were installed on the combustion chamber to measure the cylinder pressure occurred during combustion process.

In order to obtain the boundary conditions at the intake and outflow boundaries for the CFD analysis, thermocouple sensor were installed at nearest possible to the cylinder head so that the temperature of intake and exhaust ports can be determined to be employed inside CFD simulation. The fuel injection supply and ignition timing were controlled electronically by an electronic control unit (ECU) installed inside the engine.

\subsection{Numerical Comparison}

The calculated and experimental data are compared at two engine operating conditions. Case $\mathrm{A}$ is the engine running at $2000 \mathrm{rpm}$ with the start of injection timing of $130^{\circ} \mathrm{CA}$ before $\mathrm{TDC}$, the injection duration of $50^{\circ} \mathrm{CA}$, the ignition timing of $19^{\circ} \mathrm{CA}$ before TDC, the initial pressure of 1.05 bar and the initial temperature of $305 \mathrm{~K}$. Case B is the engine operating at $6000 \mathrm{rpm}$ with the start of injection timing of $210^{\circ} \mathrm{CA}$ before TDC, the injection duration of $160^{\circ} \mathrm{CA}$, the ignition timing of $28^{\circ} \mathrm{CA}$ before TDC, the initial pressure of 0.9 bar and the initial temperature of $306 \mathrm{~K}$.

Figures 30 and 31 illustrate the comparison between the calculated and experimental pressure curves for case A and $\mathrm{B}$, respectively. It is indicated that the calculated maximum pressure and combustion duration are in good agreement with the measured results for both cases. Therefore, the CFD and combustion simulation model performed in this study are able to represent the real combustion process inside CNG-DI engine and have the capability to be implemented for further calculation. As can be seen, the cylinder pressure obtained from the CFD simulation has the higher value due to the fact that the typical CFD simulations do not take into account the friction losses within engine cylinder. Thus, the numerical calculation has resulted in a value slightly higher than that given by the experimental data. In addition, the empirical coefficients for natural gas combustion from the combustion model of EBU for diffusion reaction employed here need to be adjusted to achieve a closer result of pressure from experimental data due to the higher RON for natural gas.

\section{PARAMETRIC STUDIES}

In order to optimise the performance of the CNG/DI engine with the model established and developed in this study, a set of parametric studies are executed to explore the effect of the start of injection timing and ignition timing on the engine performance in the representation of its in-cylinder pressure and emissions in the forms of its $\mathrm{CO}$ and NO emission formation. These parametric studies are based on the case A listed in Table 2 with engine speed of $2000 \mathrm{rpm}$ and different values of injection timing as well as ignition timing. The end of injection timing for these parametric studies was kept constant at $80^{\circ} \mathrm{CA}$ before TDC due to the reason on the tremendous number of design experiments generated. The first fifth design was conducted with different start of injection timing with interval $5^{\circ} \mathrm{CA}$ from $140^{\circ} \mathrm{CA}$ bTDC to $120^{\circ} \mathrm{CA}$ bTDC and the ignition timing was kept constant at $19^{\circ} \mathrm{CA}$ bTDC to examine the effect of start of injection timing firstly. Next, the start of injection timing at $130^{\circ} \mathrm{CA}$ bTDC as the baseline condition was chosen to observe the influence of ignition timing from $23^{\circ} \mathrm{CA}$ bTDC to $15^{\circ} \mathrm{CA}$ bTDC in the range of $2^{\circ} \mathrm{CA}$. Table 3 categorised the design of experiments proposed in this work for various injection and ignition timings carried out to explore these parameters to the engine performance and its pollutant formation.

For the purpose of reducing the computational cost and time, the CFD simulation for the present parametric study was carried out starting from the middle of compression stroke at $220^{\circ} \mathrm{CA}$ and finished at $40^{\circ} \mathrm{CA}$ aTDC position. However, the proper initial conditions for CFD calculation were applied to the computational mesh to provide the reasonable parameters inside combustion chamber before computation start, such as the initial pressure, temperature and amount of gases. 
By performing this simulation range of combustion process, the investigated important parameters in the present work, which are cylinder pressure, $\mathrm{CO}$ emission and NO concentration is already passed their maximum value. This condition means that the obtained value that considers to be analyzed is only the maximum or highest value and the parallel computing performance can be minimized and saved up.

\subsection{Effect of Injection Timing}

It is known that the injection timing plays an important role in influencing the engine performance and emissions so that changing the injection timing is an effective method to regulate the indicated mean effective pressure (IMEP) and pollutant formations. If the injection timing is done earlier, more fuel is injected into cylinder hence producing the higher in-cylinder pressure and otherwise. To study the effect of injection timing on engine performance and its emissions, the baseline case was compared to other four case studies in which the start of injection timing was changed by advance and retarding it with the interval of $5^{\circ} \mathrm{CA}$. Hence, the fuel injection was assumed to occur from $140^{\circ} \mathrm{CA}$ bTDC to $120^{\circ} \mathrm{CA}$ bTDC i.e. design number 1 to 5 .

The results for the effect of injection timing are shown in Fig. 32. From Fig. 32(a) it can be observed that the peak pressure increases when natural gas is injected earlier, as expected due to the reason that more fuel is contained within engine cylinder to raise the pressure during the combustion process. The behaviour of $\mathrm{CO}$ formation in the percentage of mass fraction can be studied in Fig. 32(b). The amount of $\mathrm{CO}$ attains its maximum value at the injection timing of $140^{\circ} \mathrm{CA}$ bTDC followed by the subsequent design numbers due to the effect of the fuel quantity to be burned completely and its poor oxidation process to convert $\mathrm{CO}$ to become $\mathrm{CO}_{2}$. Other than that, the earlier injection timing has a higher fuel concentration inside cylinder and this will cause a more $\mathrm{CO}$ produced. The NO traces for different injection timings is presented in Fig. 32(c) which reaches its maximum value at $140^{\circ}$ CA bTDC because of its relatively higher combustion temperature. Other than temperature, the production of NO depends on pressure, air-fuel ratio and combustion time within the engine cylinder. Such phenomena can be detected from design number 4 and 5, which represent the excess air due to the late fuel injection timing. The smallest amount of NO was produced at design number 2 where the production rate of NO is quite slower compared to the other design number even though the fuel is injected earlier and has higher temperature. The production of NO is also very sensitive to the local air-fuel equivalence ratio, especially around spark plug area where the ignition begins. The results produced from the baseline condition have relatively lower NO concentration and prove that the control of start of injection timing has influenced the emission formation of NO.

\subsection{Effect of Ignition Timing}

The other method to increase the engine performance for obtaining the higher in-cylinder pressure to be transferred to become power and torque is through advancing the spark ignition timing. Spark timing has a considerable effect on engine performance, efficiency and exhaust emission. Starting the ignition too early from TDC position can result in a very high gas pressure acting on the piston during compression stroke. However, it will have a consequence to produce the increased negative work in compression stroke and decreased positive work in expansion stroke so that the low average torque will be generated. In addition, too-early ignition sometimes also can cause abnormal combustion phenomenon, which usually causes piston knocking.

On the other hand, too-late ignition results in low gas pressure inside cylinder and thus low effective work to produce power. The determination of setting the ignition timing depends on the engine design, operating conditions, properties of fuel and air and burned gas mixture. The time from ignition starts to reach the maximum gas pressure in the cylinder changes slightly depend on the engine operating conditions. Hence, with increasing engine speed, the spark advance should be increased to obtain a proper combustion pressure within cylinder. The correct spark timing is necessary because $\mathrm{CO}$ and $\mathrm{NO}$ emissions vary significantly with spark timing.

In order to study the effect of ignition timing on engine performance and emissions, the baseline case with the ignition timing at $19^{\circ} \mathrm{CA}$ bTDC was evaluated by comparing it to the other four case studies in which the ignition timing was modified by advance and retarding it with the interval of $2^{\circ} \mathrm{CA}$. The start and end of injection timing was fixed at $130^{\circ} \mathrm{CA}$ and $80^{\circ} \mathrm{CA}$ bTDC, respectively. Therefore, the ignition timing was positioned to occur from $23^{\circ} \mathrm{CA}$ bTDC to $15^{\circ} \mathrm{CA}$ bTDC i.e. design number 6 to 10 . The obvious outcome to the advanced ignition timing is the higher in-cylinder pressure. However, it will have higher NO concentration as the consequence of higher combustion temperature. The behaviour of $\mathrm{CO}$ emission follows the increment of in-cylinder pressure until reaching its peak value before decreasing significantly at the end of exhaust stroke. It can be seen in Fig. 33(a) that the in-cylinder pressure reaches the higher value from the action of advancing ignition timing due to the complete combustion from earlier ignition timing. In here, the amount of fuel can burn perfectly so that produces the smaller $\mathrm{CO}$ emission as shown in Fig. 33(b).

Based on the combustion theory, the spark timing significantly affects the NO emission levels. Advancing the timing so that combustion occurs earlier increases the peak cylinder pressure because more fuel is burned before TDC and the peak pressure moves closer to TDC where the cylinder volume is smaller. On the other side, retarding the timing decreases the peak cylinder pressure because more of the fuel burns after TDC. The higher peak cylinder pressure generates the higher peak burned gas temperature and hence the higher NO formation rates. Figure 33(c) shows that the highest NO emission value will be produced from the earlier spark ignition timing, which is at $23^{\circ}$ CA bTDC followed by the subsequent ignition timing.

\section{CONCLUSION}

The CFD modelling of fuel injection, spark ignition, combustion and pollutant formation were performed to simulate these phenomena and processes in a compressed natural gas direct injection engine. The details of the engine geometry chosen for the calculations were given along with and explanation for the modelling choices 
made. A baseline operating regime was taken as low engine speed (2000 rpm), high load (stoichiometric condition), medium injection timing $\left(130^{\circ} \mathrm{CA}\right.$ bTDC) and medium ignition timing $\left(19^{\circ} \mathrm{CA}\right.$ bTDC) to simulate the detailed combustion process which occurred in such engine.

The results obtained for the baseline case were examined in depth and were found to agree qualitatively with known literature. The main conclusions drawn from this work can be summarized as follows:

(1) The calculated and experimental data shows a close agreement in predicting the combustion pressure for two case studies, which confirming the accuracy of the CFD and combustion model employed in the present study.

(2) The fuel injection timing plays an important role on the engine performance, combustion and emissions because it influences the time of fuel air mixing shortly before spark ignition begins. The retard of fuel injection reduces $\mathrm{CO}$ in the exhaust but increases NO emission due to the excess of air in the mixture, and decreases the combustion pressure. Slightly retarding fuel injection could be an option to decrease the $\mathrm{CO}$ and $\mathrm{NO}$ formation without significantly compromising engine performance.

(3) The spark ignition timing is one of important parameters to be taken into account to design the optimum engine parameters as well. Advancing ignition timing results in better cylinder pressure and lower $\mathrm{CO}$ emission but increasing the NO level. Setting ignition timing not too advance from TDC position could be an effective strategy to reduce NO when high performance from engine is desired.

In general, the results of the present work can contribute the reference guide for the design and development of the new engine concept and its combustion system.

\section{ACKNOWLEDGEMENTS}

The authors would like to thank the Ministry of Science, Technology \& Innovation of Malaysia for sponsoring this work under project IRPA 03-02-02-0057PR0030/10-04.

\section{REFERENCES}

Agarwal, A. and Assanis, D. (2000). "Multi-dimensional modelling of ignition, combustion and nitric oxide formation in direct injection natural gas engines", SAE Technical Paper 2000-01-1839.

Ando, T., Isobe, Y., Sunohara, D., Daisho, Y. and Kusaka, J. (2003). "Homogeneous charge compression ignition and combustion characteristics of natural gas mixtures: the visualization and analysis of combustion", JSAE Review, Vol. 24, pp. 33-40.
Aslam, M.U., Masjuki, H.H., Kalam, M.A., Abdesselam, H., Mahlia, T.M.I. and Amalina, M.A. (2006). “An experimental investigation of $\mathrm{CNG}$ as an alternative fuel for a retrofitted gasoline vehicle", Fuel, Vol. 85 , pp. 717-724.

El-Tahry, S.H (1983). " $k-\varepsilon$ equation for compressible reciprocating engine flows", Journal of Energy, Vol. 7, No. 4, pp. 345-353.

Fergusson, C.R. and Kirkpatrick, A.T. (2001). Internal combustion engines applied thermosciences, John Wiley and Sons, New York, USA.

Heywood, J.B. (1988). Internal combustion engine fundamentals. McGraw-Hill, New York, USA.

Kusaka, J., Okamoto, T., Daisho, Y., Kihara, R. and Saito, T. (2000). "Combustion and exhaust gas emission characteristics of a diesel engine dualfuelled with natural gas", JSAE Review, Vol. 21, pp. 489-496.

Magnussen, B.F. (1981). "On the structure of turbulence and a generalised eddy dissipation concept for chemical reaction in turbulent flow", Proceedings of $19^{\text {th }}$ AIAA Aerospace Meeting, St. Louis, United States, July.

Olikara, C. and Borman, G. (1975). "A computer program for calculation properties of equilibrium combustion products with some applications to IC engines", SAE Paper 750468.

Pulkrabek, W.W. (2004). Engineering fundamentals of the internal combustion engine, Prentice-Hall, New Jersey, USA.

Shiga, S., Ozone, S., Machacon, H.T.C., Karasawa, T., Nakamura, H., Ueda, T., Jingu, N., Huang, Z., Tsue, M. and Kono, M. (2002). "A study of the combustion and emission characteristics of compressed-natural-gas direct-injection stratified combustion using a rapid-compression-machine", Combustion and Flame, Vol. 129, pp. 1-10.

Zhang, D. and Frankel, S.H. (1998). "A numerical study of natural gas combustion in a lean burn engine", Fuel, Vol. 77, No. 12, pp. 1339-1347.

Zeng K., Huang, Z., Liu, B., Liu, L., Jiang, D., Ren, Y. and Wang, J. (2006). "Combustion characteristics of a direct-injection natural gas engine under various fuel injection timings", Applied Thermal Engineering, Vol. 26, pp. 806-813.

Zheng, Q.P., Zhang, H.M. and Zhang, D.F. (2005). “A computational study of combustion in compression ignition natural gas engine with separated chamber", Fuel, Vol. 84, pp. 1515-1523. 
Table 1 Specifications of CNG-DI engine

\begin{tabular}{|c|c|c|}
\hline Engine parameter & Value & Unit \\
\hline Number of cylinders & 4 & - \\
\hline Type & Inline & - \\
\hline Displacement volume & 1596 & $\mathrm{~cm}^{3}$ \\
\hline Bore & 78 & $\mathrm{~mm}$ \\
\hline Stroke & 84 & $\mathrm{~mm}$ \\
\hline Connecting rod length & 131 & $\mathrm{~mm}$ \\
\hline Crank radius & 44 & $\mathrm{~mm}$ \\
\hline Compression ratio & 10 & - \\
\hline Intake valve opening & 12 & $\mathrm{bTDC}$ \\
\hline Intake valve closing & 48 & $\mathrm{aBDC}$ \\
\hline Exhaust valve opening & 45 & $\mathrm{bBDC}$ \\
\hline Exhaust valve closing & 10 & $\mathrm{aTDC}$ \\
\hline Maximum intake valve lift & 8.1 & $\mathrm{~mm}$ \\
\hline Maximum exhaust valve lift & 7.5 & $\mathrm{~mm}$ \\
\hline
\end{tabular}

Table 2 Engine operating conditions

\begin{tabular}{|c|c|c|}
\hline Parameters & Case A & Case B \\
\hline Engine speed (rpm) & 2000 & 6000 \\
\hline Mass flow rate (g/s) & 0.505 & 1.250 \\
\hline Equivalence ratio & 1.0 & 1.0 \\
\hline Intake port temperature (K) & 305 & 306 \\
\hline Intake port pressure (bar) & 1.05 & 0.90 \\
\hline Start of injection timing ( ${ }^{\circ}$ bTDC) & 130 & 210 \\
\hline End of injection timing ( ${ }^{\circ}$ bTDC) & 80 & 160 \\
\hline Ignition timing $\left({ }^{\circ}\right.$ bTDC) & 19 & 28 \\
\hline
\end{tabular}

Table 3 Design of experiments for various injection and ignition timing

\begin{tabular}{|c|c|c|}
\hline Design Number & Start of Injection (bTDC) & Spark Advance (bTDC) \\
\hline Design 1 & 140 & 19 \\
\hline Design 2 & 135 & 19 \\
\hline Design 3 & 130 & 19 \\
\hline Design 4 & 125 & 19 \\
\hline Design 5 & 120 & 19 \\
\hline Design 6 & 130 & 23 \\
\hline Design 7 & 130 & 21 \\
\hline Design 8 & 130 & 19 \\
\hline Design 9 & 130 & 17 \\
\hline Design 10 & 130 & 15 \\
\hline
\end{tabular}




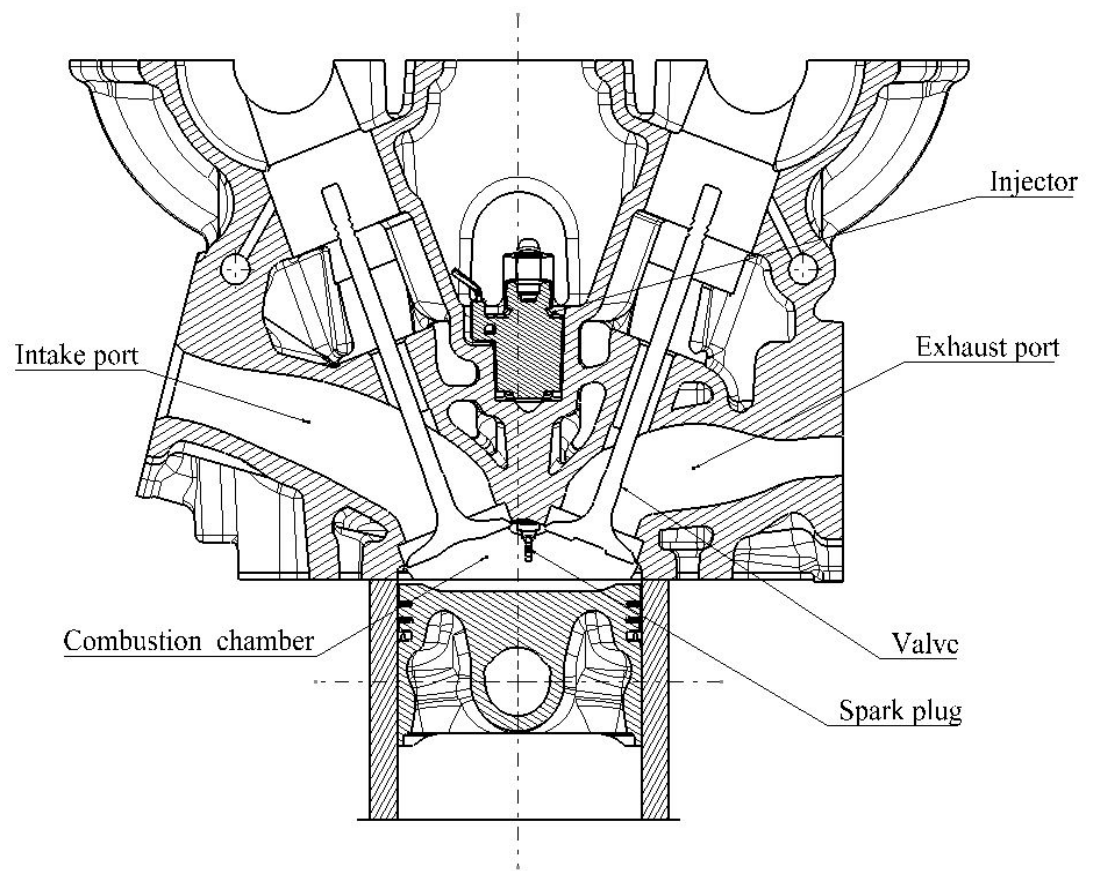

Fig. 1. The geometrical details of CNG-DI engine.

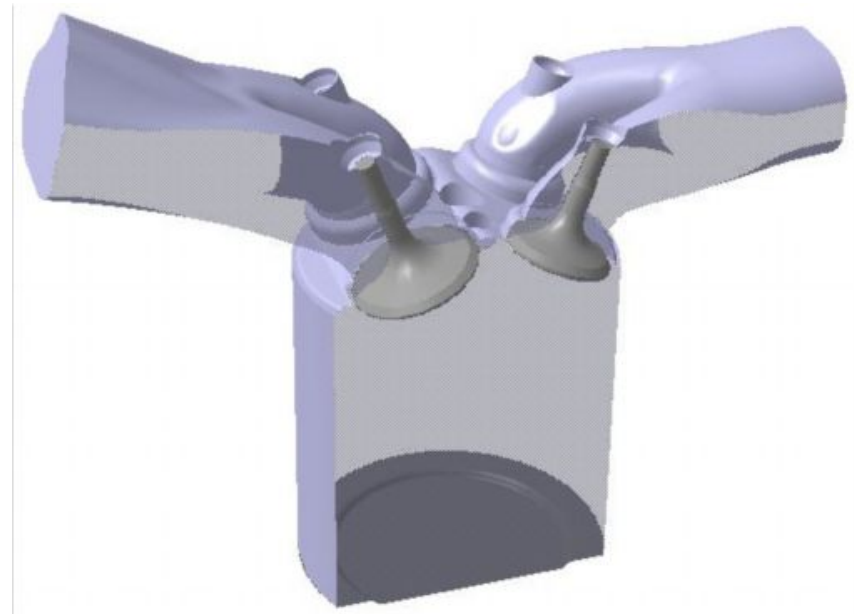

Fig. 2. A schematic view of CNG-DI engine with flat piston.

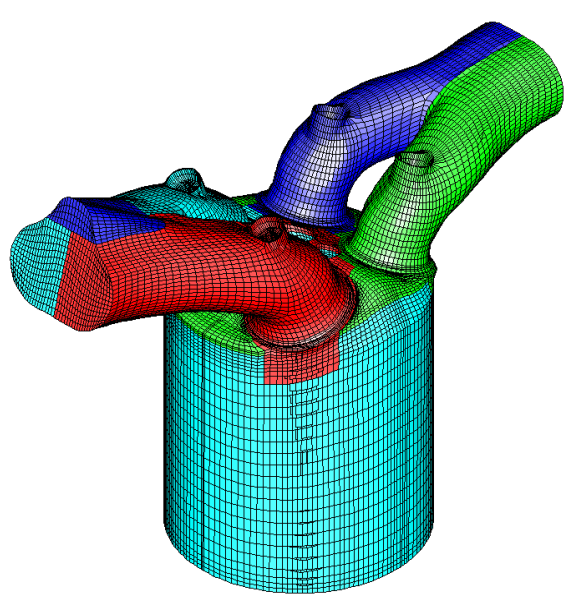

(a)

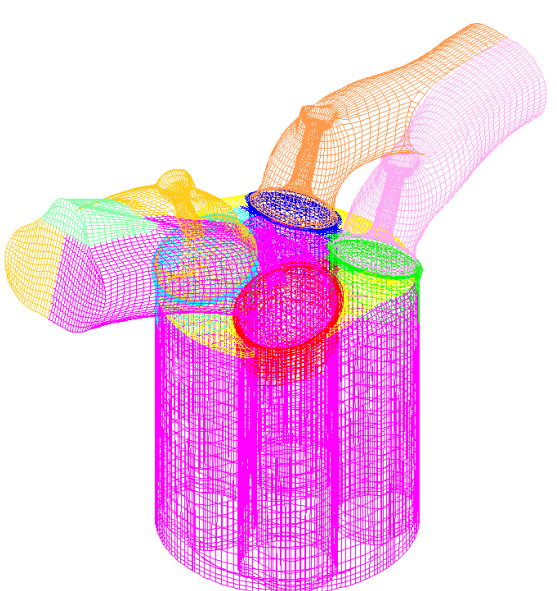

(b)

Fig. 3. A schematic view and wire mesh of the computational grid at BDC. 


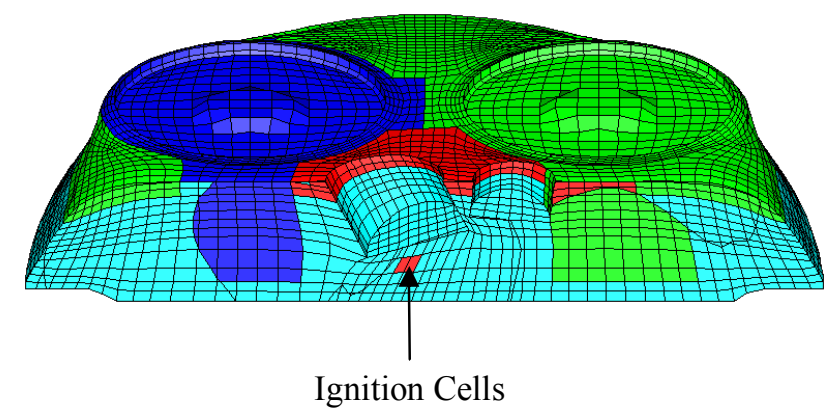

Fig. 4. Combustion chamber geometry with the ignition cells at TDC position.

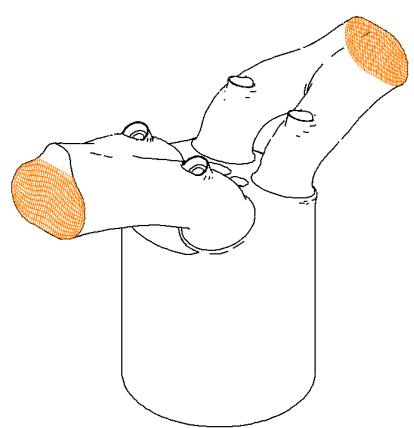

(a)

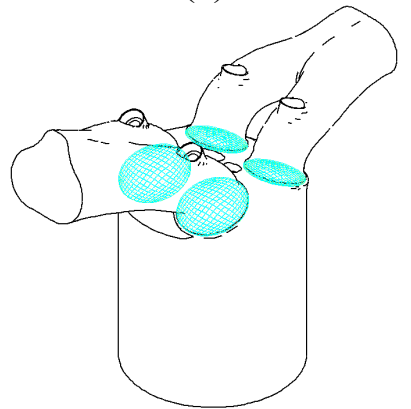

(d)

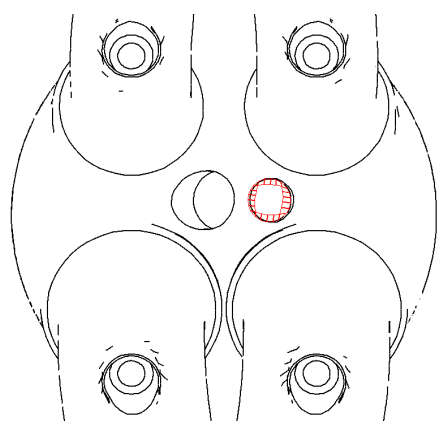

(b)

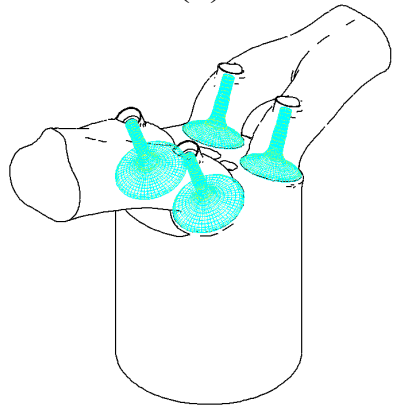

(e)

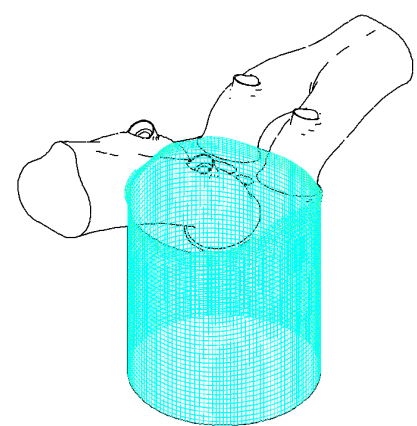

(c)

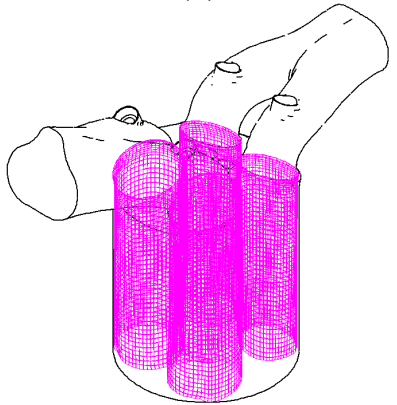

(f)

Fig. 5. Boundaries conditions of engine modelling for (a) pressure, (b), fuel inlet (c) cylinder walls, (d) lower valve walls, (e) upper valve walls and (f) attach

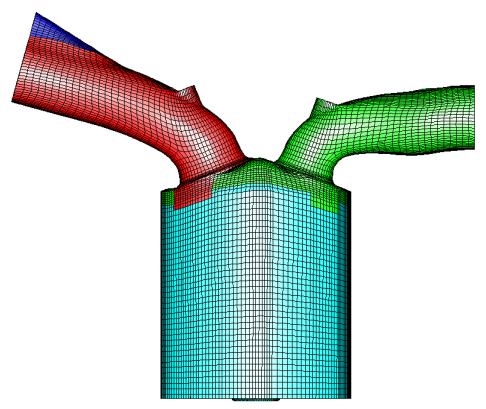

(a)

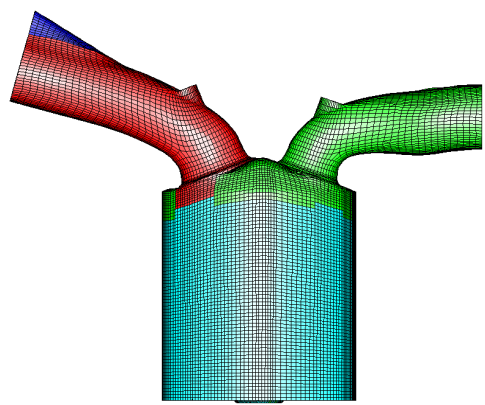

(b)

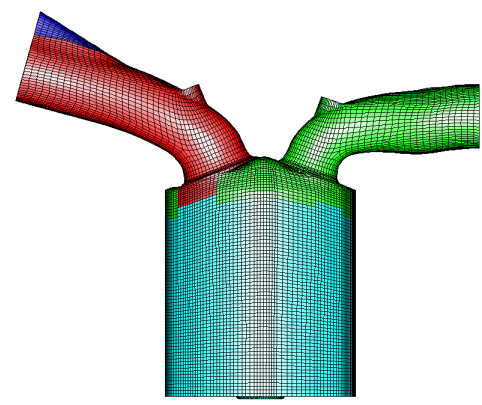

(c)

Fig. 6. A grid dependency test of engine computational configuration. 
S. Abdullah et al. / JAFM, Vol. 1, No. 2, pp. 65-86, 2008.

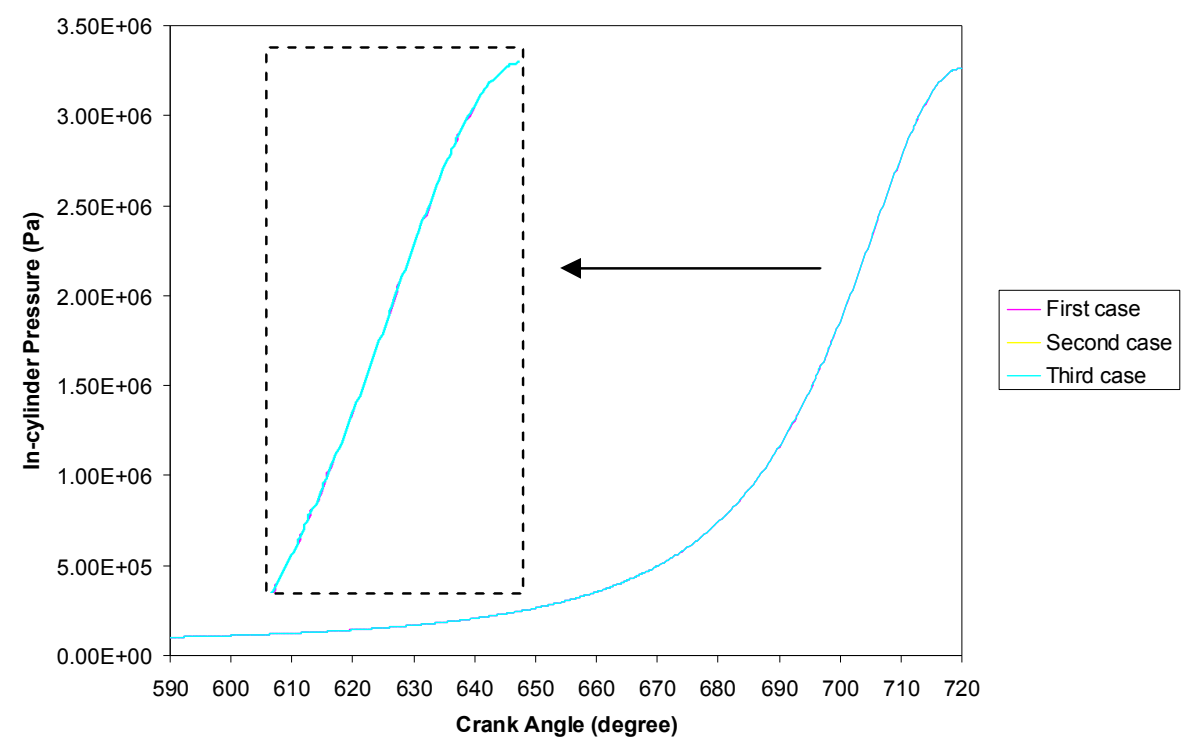

Fig. 7. In-cylinder pressure for a grid dependency test.

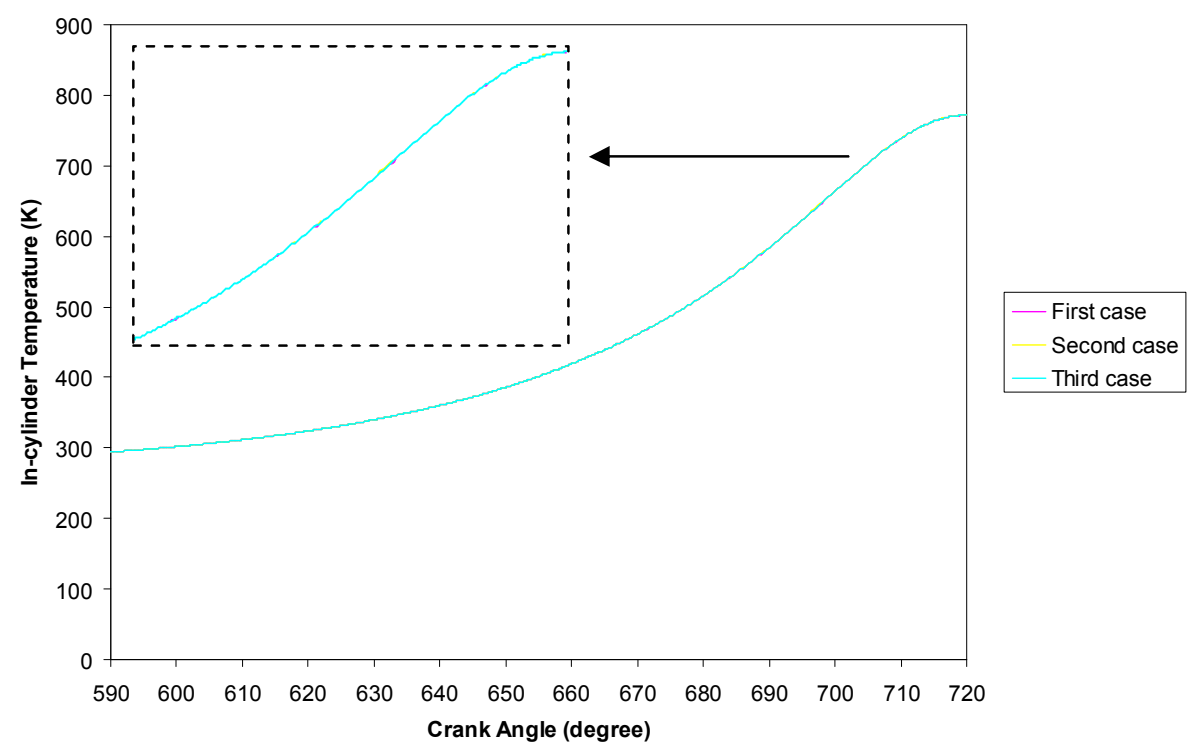

Fig. 8. In-cylinder temperature for a grid dependency test.

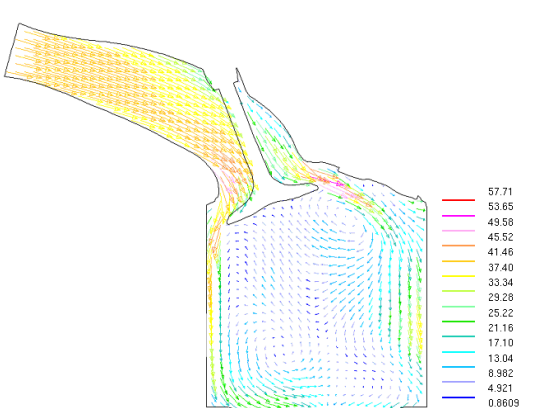

(a)

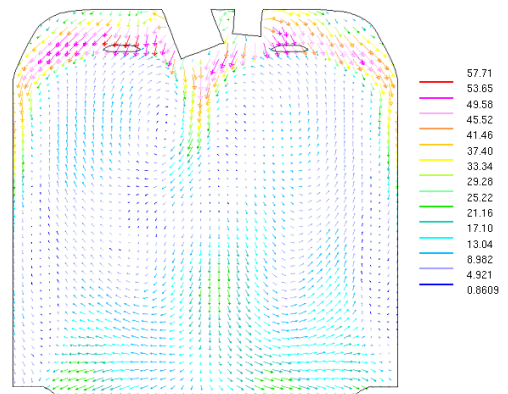

(b)

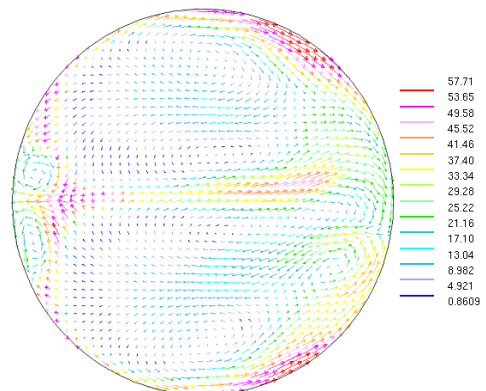

(c)

Fig. 9. Velocity vector field of baseline condition during maximum intake valves lift. 


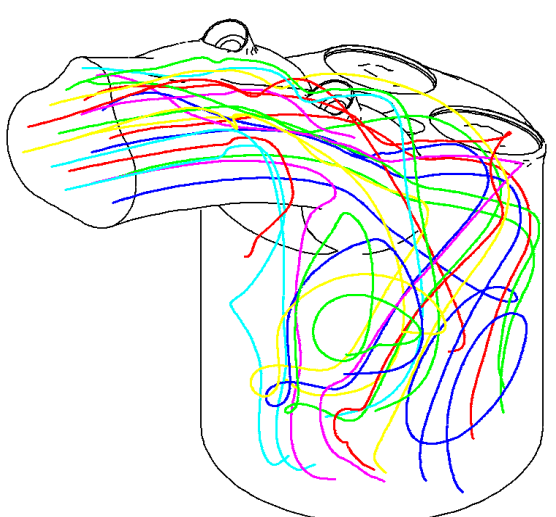

(a)

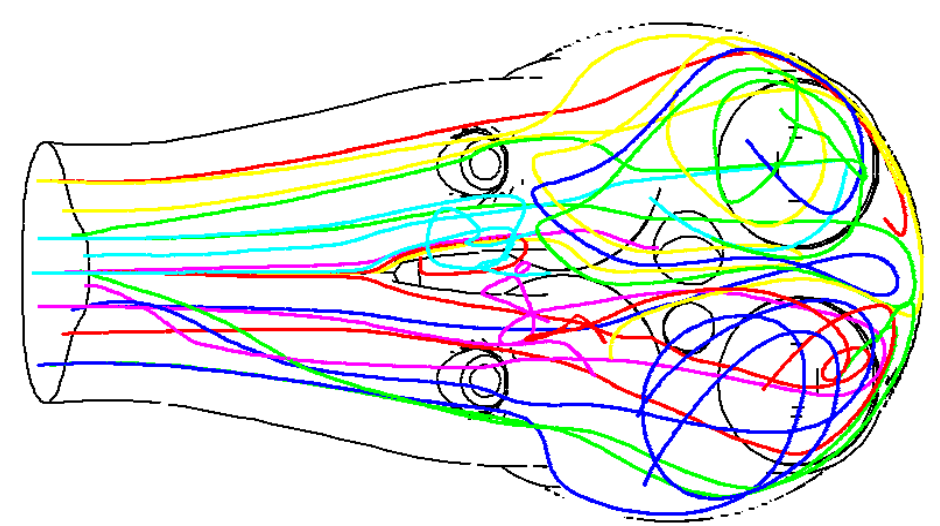

(b)

Fig. 10. Computed streamlines during maximum intake valves lift showing the swirl and tumble structure as large scale motion.
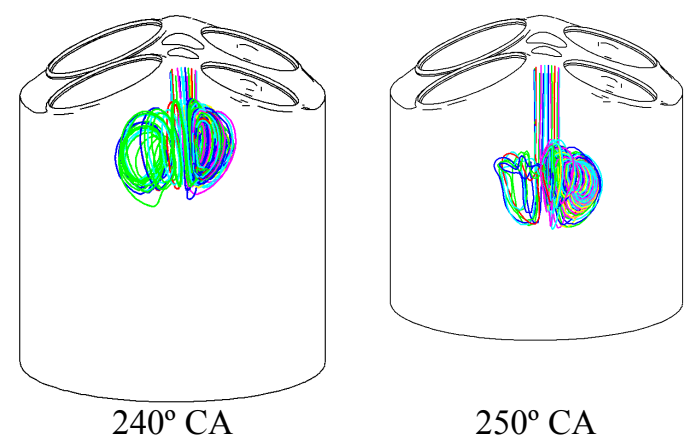

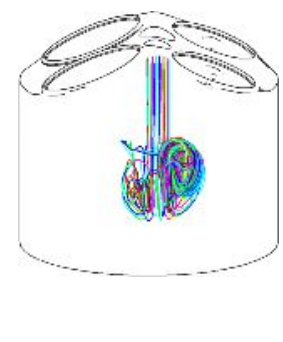

$260^{\circ} \mathrm{CA}$

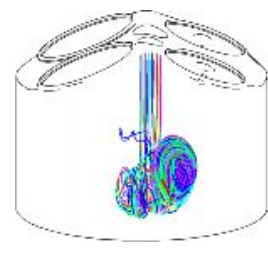

$280^{\circ} \mathrm{CA}$

Fig. 11. Computed streamlines of fuel injection at different crank angle position.

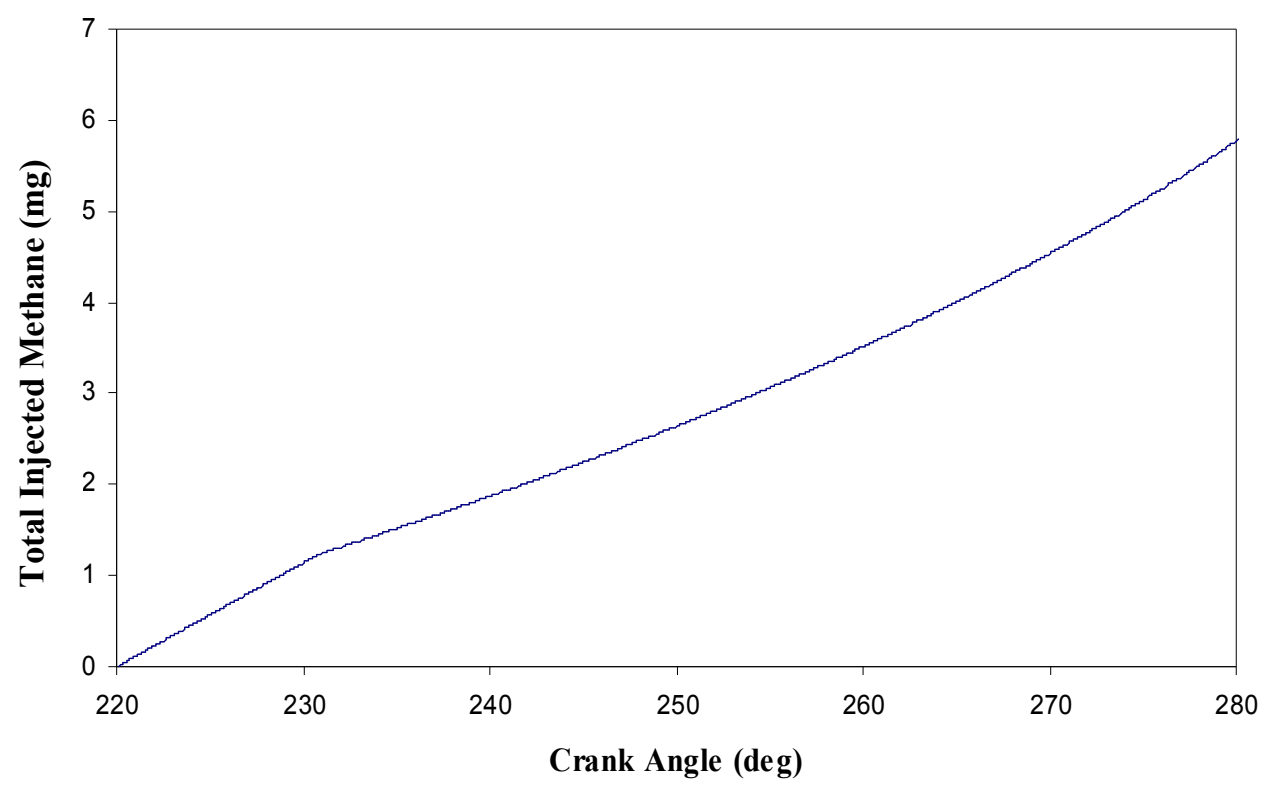

Fig. 12. Mass of injected methane. 


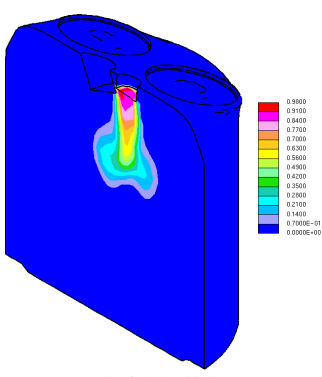

$240^{\circ} \mathrm{CA}$

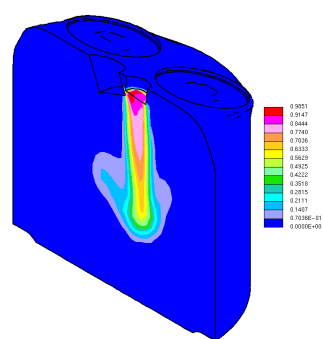

$250^{\circ} \mathrm{CA}$

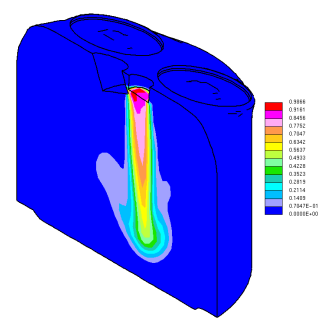

$260^{\circ} \mathrm{CA}$

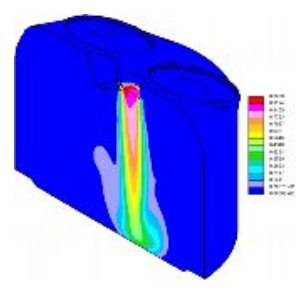

$280^{\circ} \mathrm{CA}$

Fig. 13. Mixture formation for different angle during injection process.

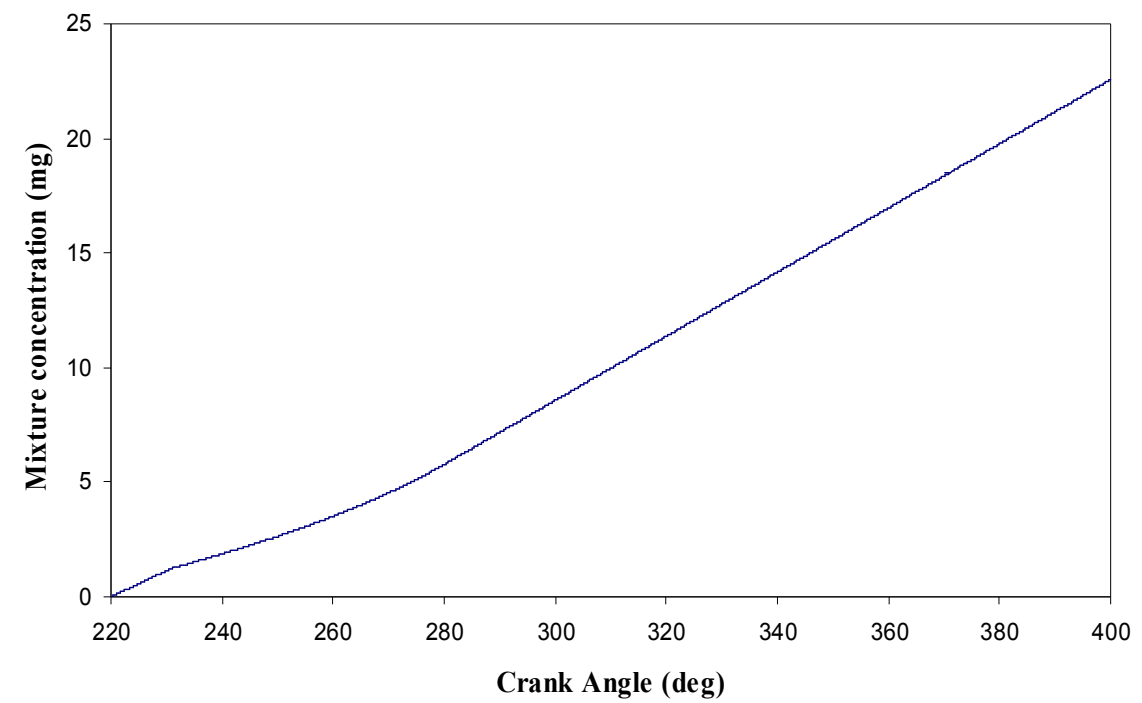

Fig. 14. The mixture distribution of air and fuel.

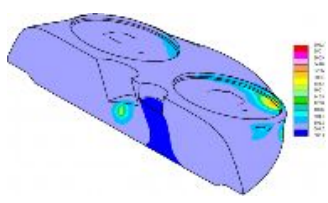

$348^{\circ} \mathrm{CA}$

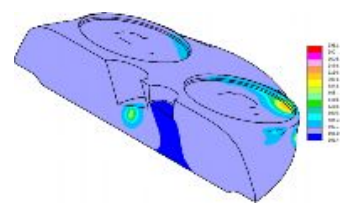

$350^{\circ} \mathrm{CA}$

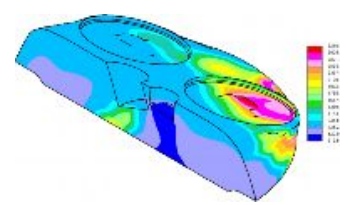

$360^{\circ} \mathrm{CA}$

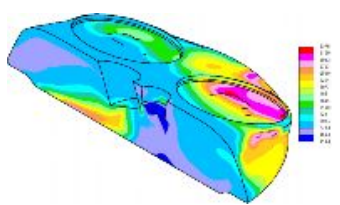

$370^{\circ} \mathrm{CA}$

Fig. 15. Temperature contour during combustion process.

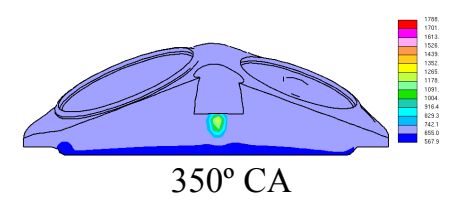

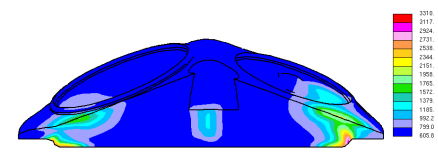

$360^{\circ} \mathrm{CA}$

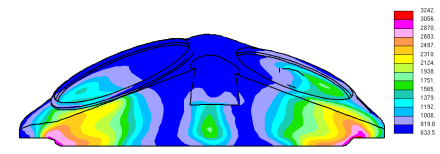

$370^{\circ} \mathrm{CA}$

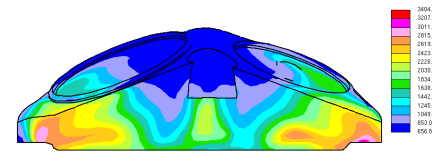

$380^{\circ} \mathrm{CA}$

Fig. 16. Temperature contour showing the flame propagation within engine cylinder. 


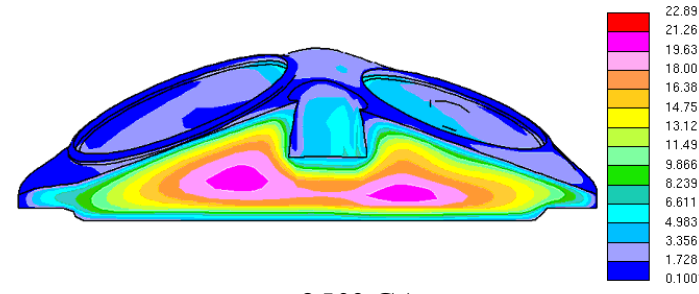

$350^{\circ} \mathrm{CA}$

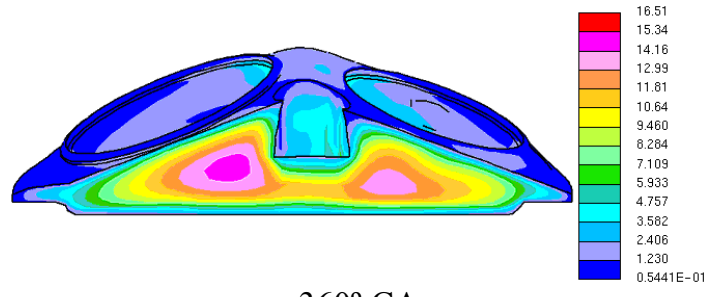

$360^{\circ} \mathrm{CA}$

Fig. 17. Distribution of turbulence kinetic energy within engine cylinder.

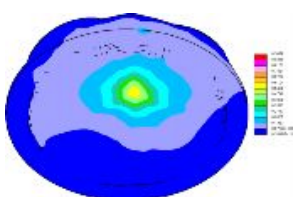

$350^{\circ} \mathrm{CA}$

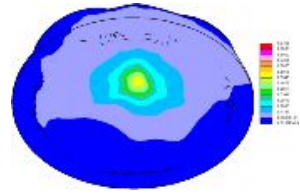

$360^{\circ} \mathrm{CA}$

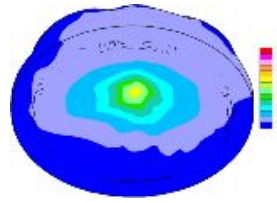

$380^{\circ} \mathrm{CA}$

$380^{\circ} \mathrm{CA}$

Fig. 18. Mass fraction of burned fuel.

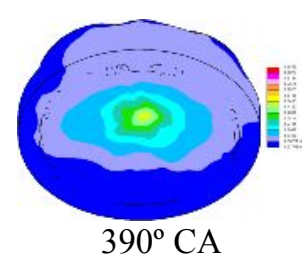

$390^{\circ} \mathrm{CA}$

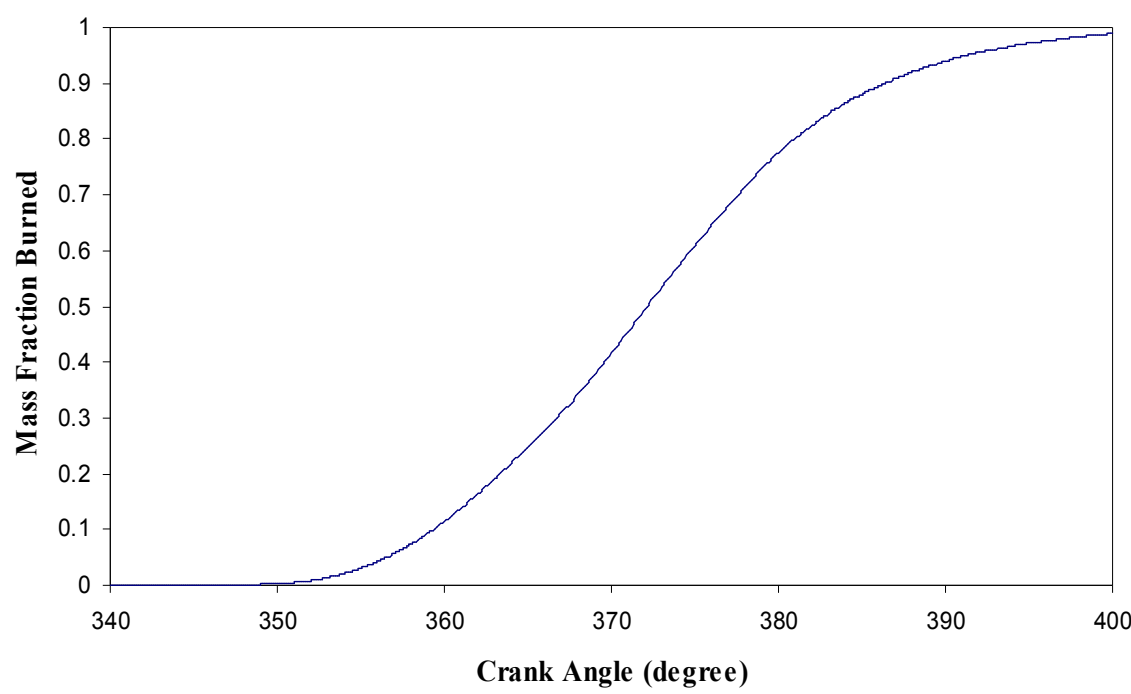

Fig. 19. Mass fraction burned.

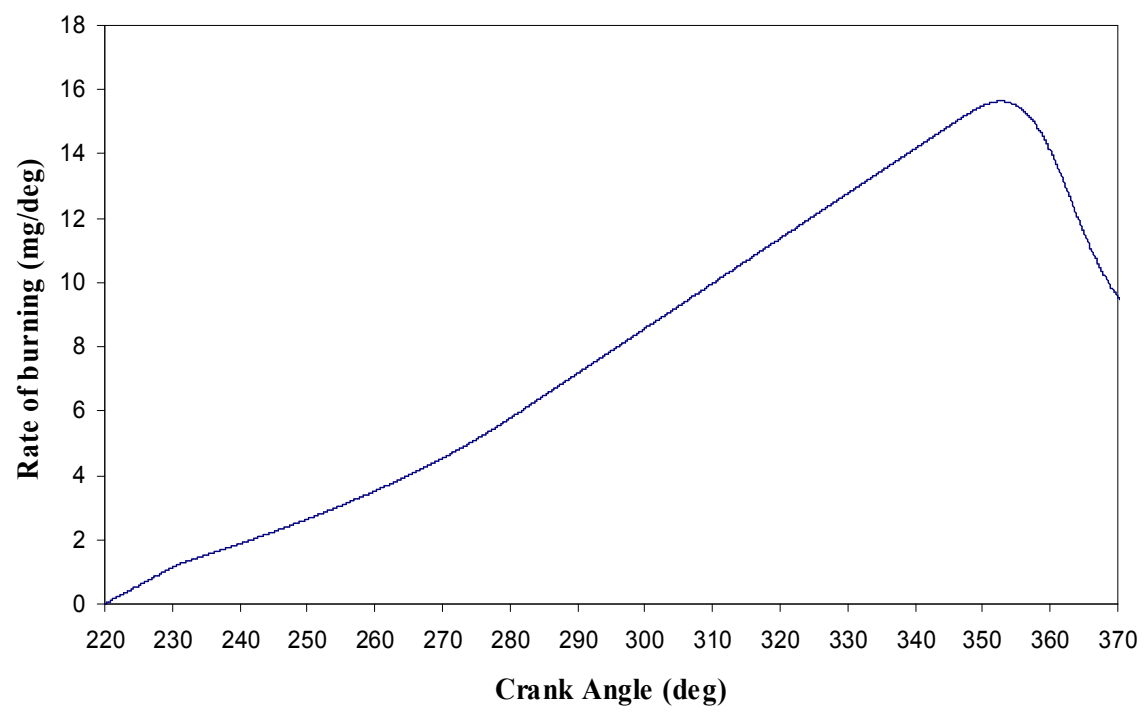

Fig. 20. Rate of burned fuel. 


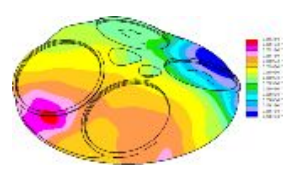

$360^{\circ} \mathrm{CA}$

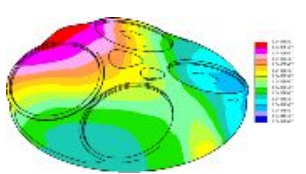

$370^{\circ} \mathrm{CA}$

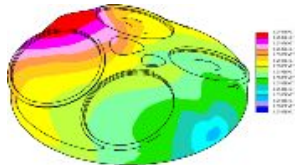

$380^{\circ} \mathrm{CA}$

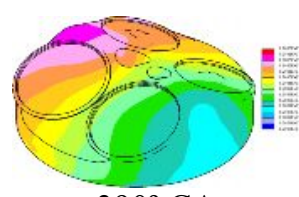

$390^{\circ} \mathrm{CA}$

Fig. 21. Contour of combustion pressure.

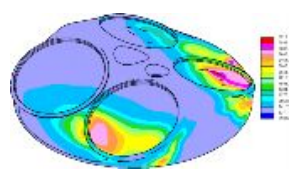

$360^{\circ} \mathrm{CA}$

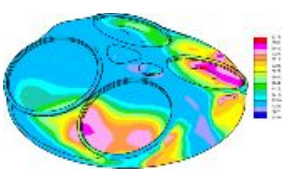

$370^{\circ} \mathrm{CA}$

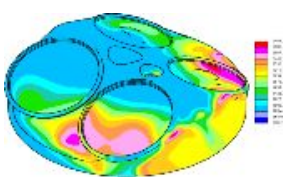

$380^{\circ} \mathrm{CA}$

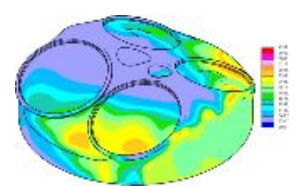

$390^{\circ} \mathrm{CA}$

Fig. 22. Contour of combustion temperature.

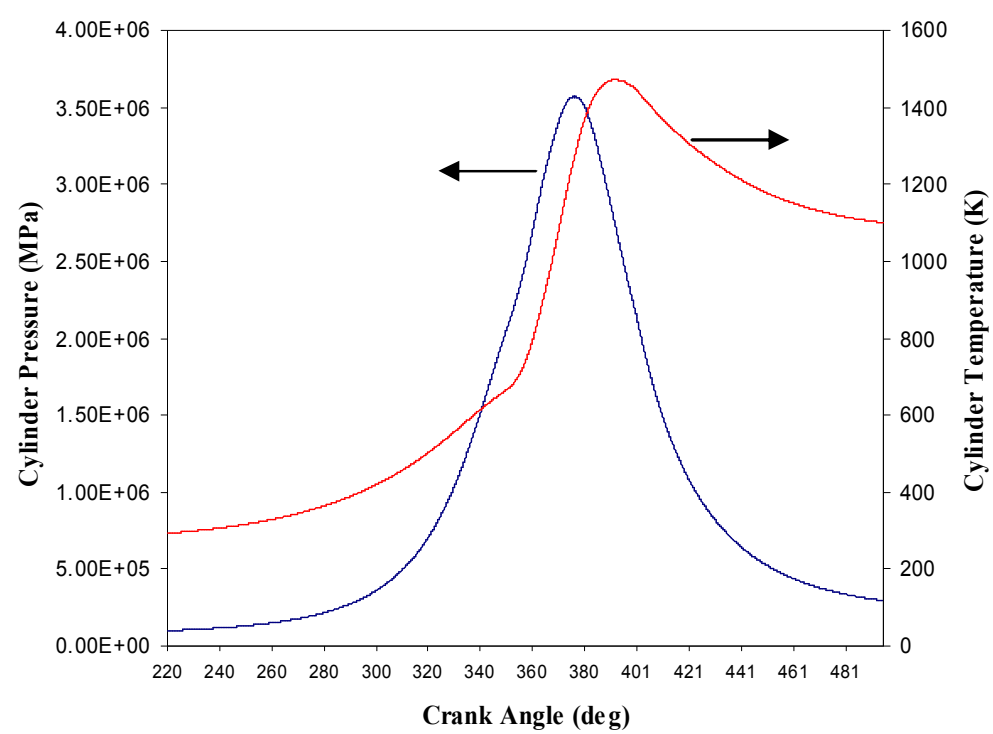

Fig. 23. Variations of mass-averaged in-cylinder pressure and temperature versus crank angle.

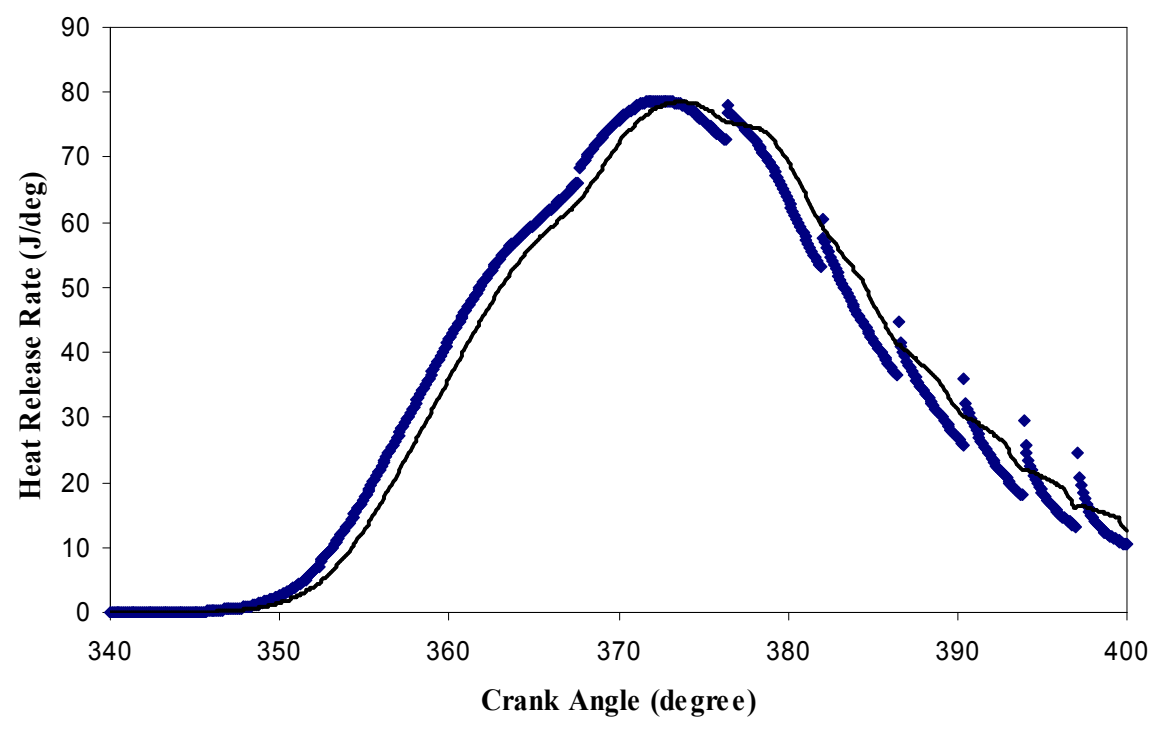

Fig. 24. Heat release rate versus crank angle. 


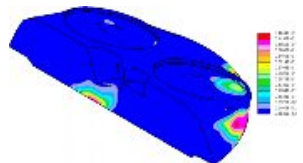

$360^{\circ} \mathrm{CA}$

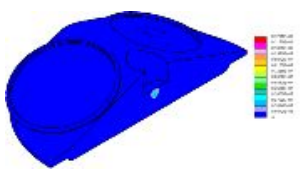

$360^{\circ} \mathrm{CA}$

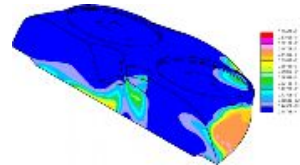

$370^{\circ} \mathrm{CA}$

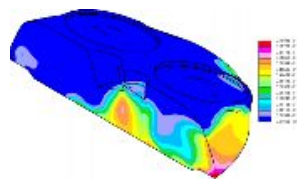

$380^{\circ} \mathrm{CA}$

Fig. 25. CO emission formation.

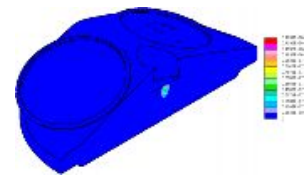

$380^{\circ} \mathrm{CA}$

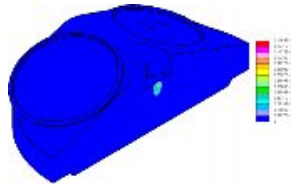

$390^{\circ} \mathrm{CA}$

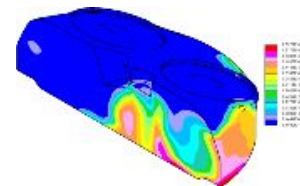

$390^{\circ} \mathrm{CA}$

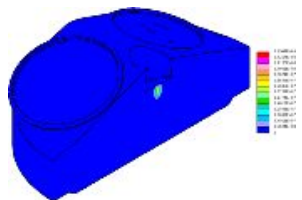

$400^{\circ} \mathrm{CA}$

Fig. 26. $\mathrm{NO}$ emission formation.

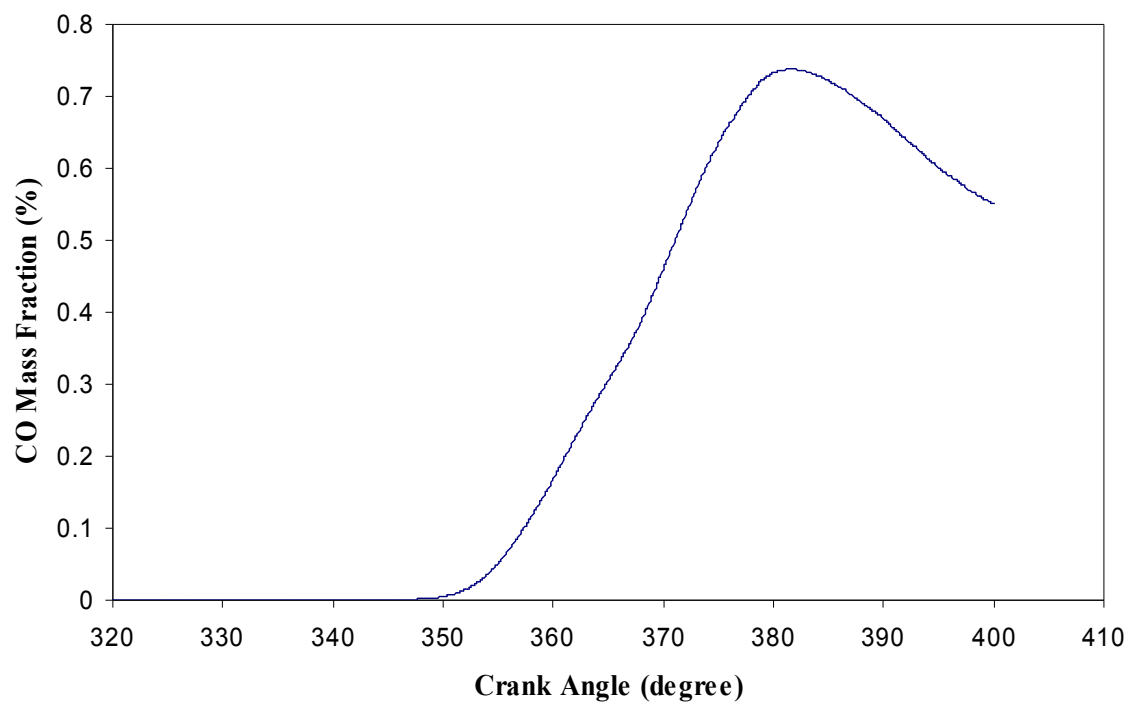

Fig. 27. Variation of $\mathrm{CO}$ emission formation.

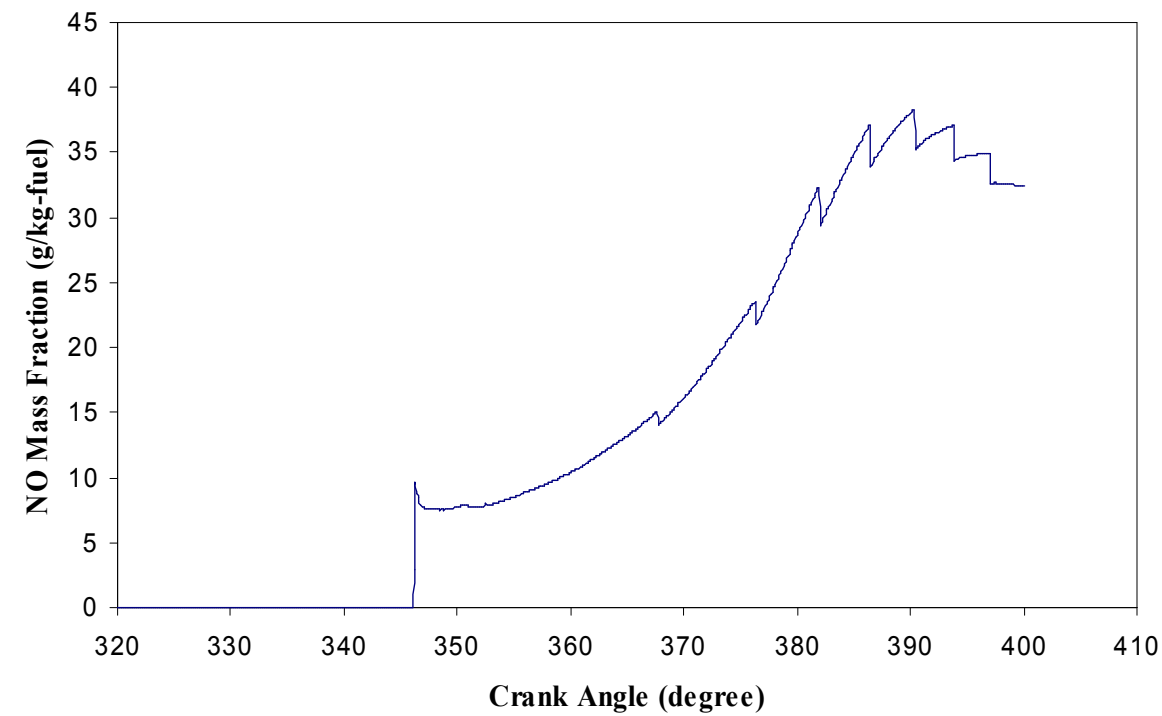

Fig. 28. Variation of NO emission formation. 

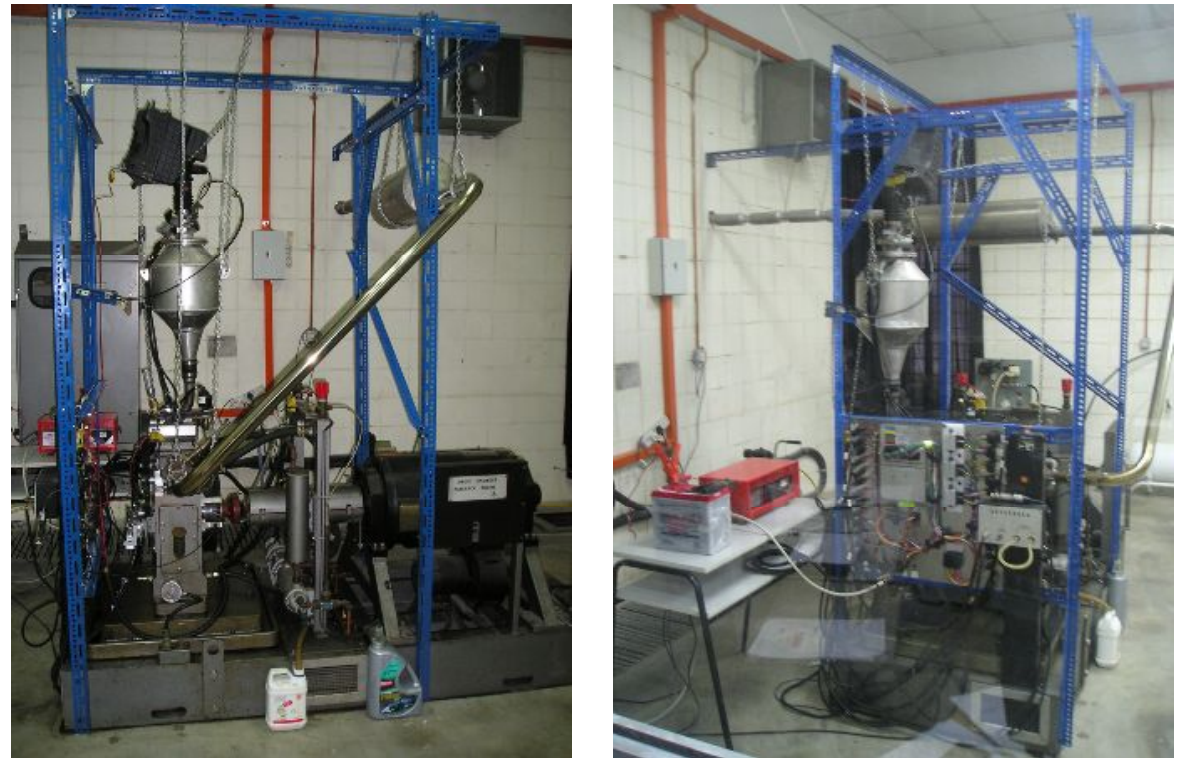

Fig. 29. The SCRE test rig of CNG-DI engine.

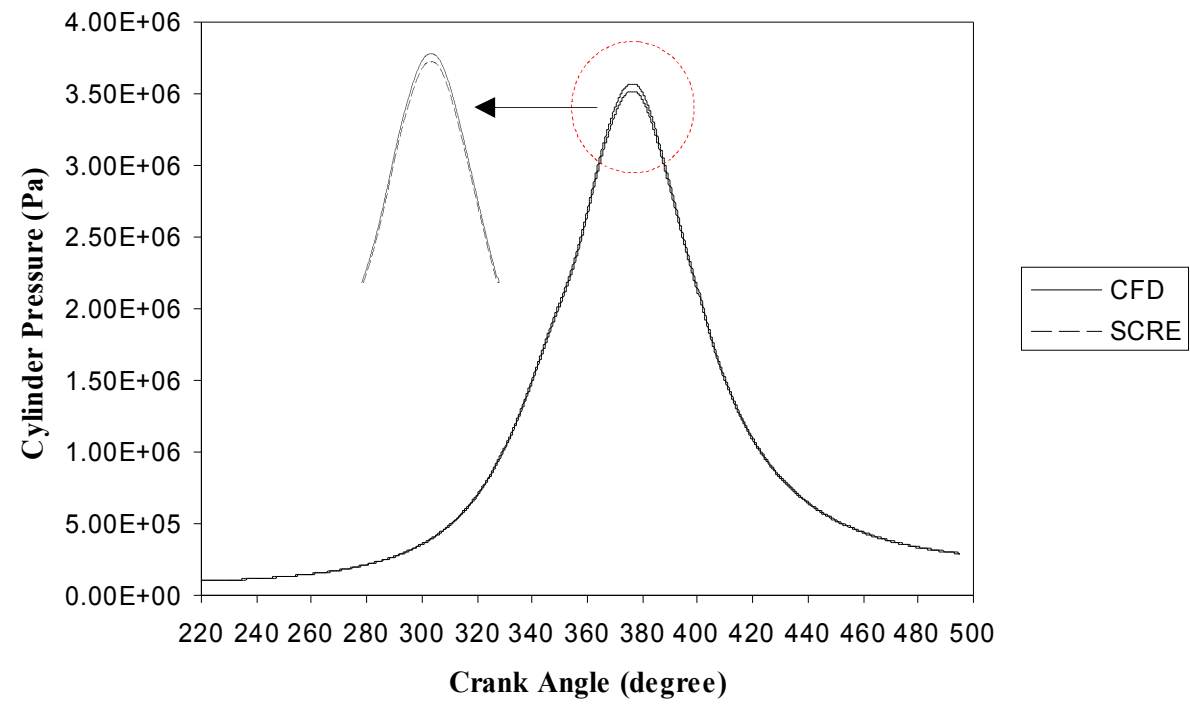

Fig. 30. Comparison of calculated and measured in-cylinder pressure for case A.

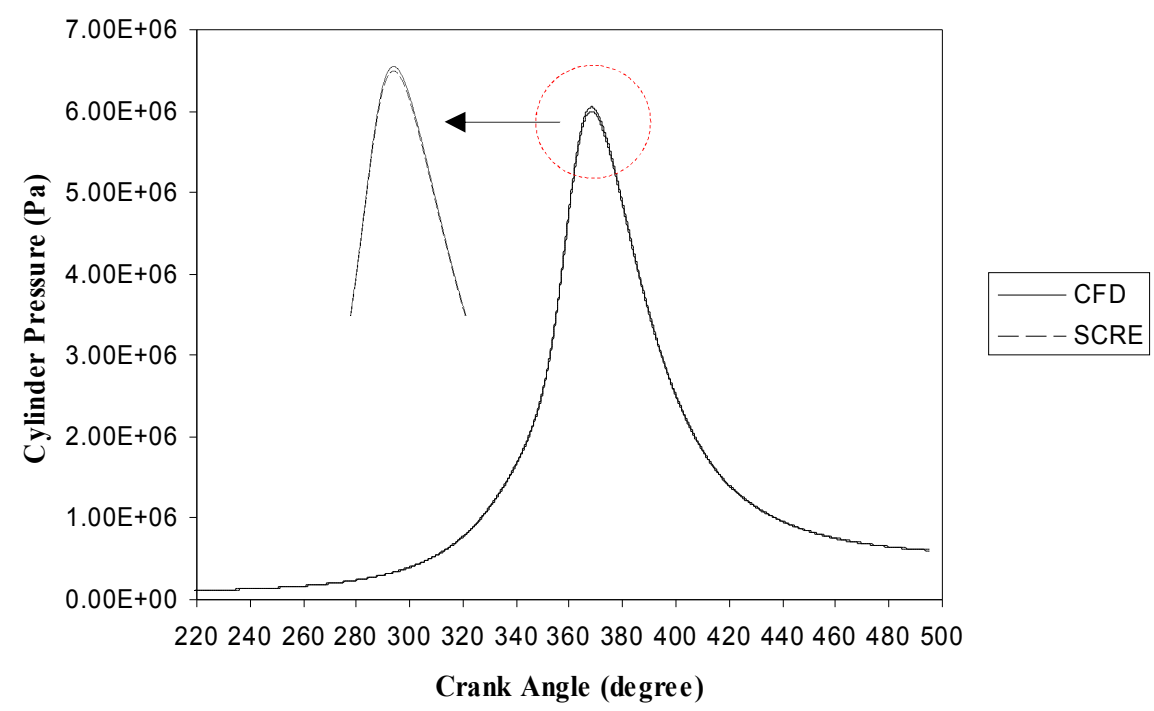

Fig. 31. Comparison of calculated and measured in-cylinder pressure for case B. 
S. Abdullah et al. / JAFM, Vol. 1, No. 2, pp. 65-86, 2008.
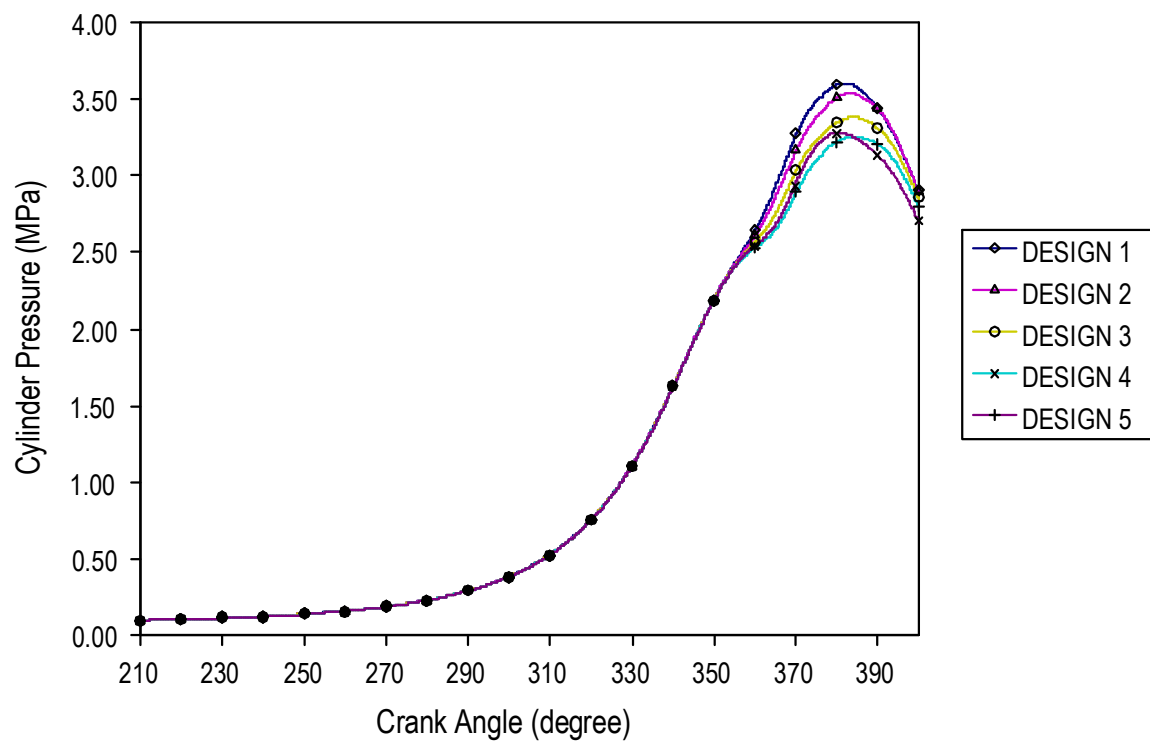

(a)
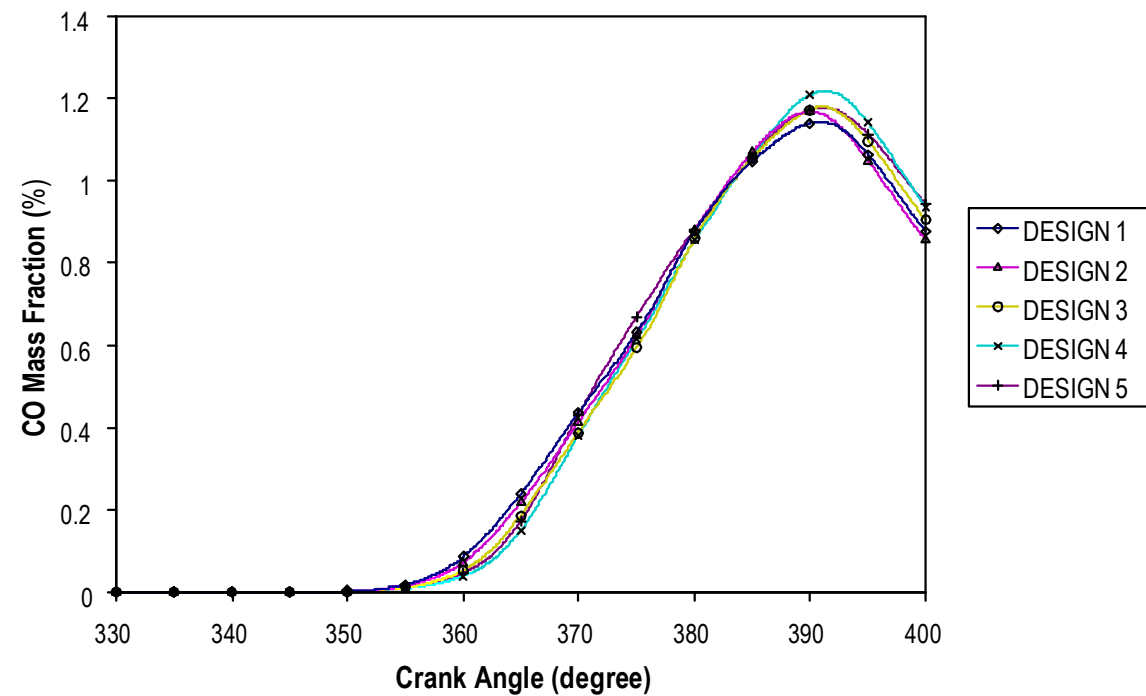

(b)

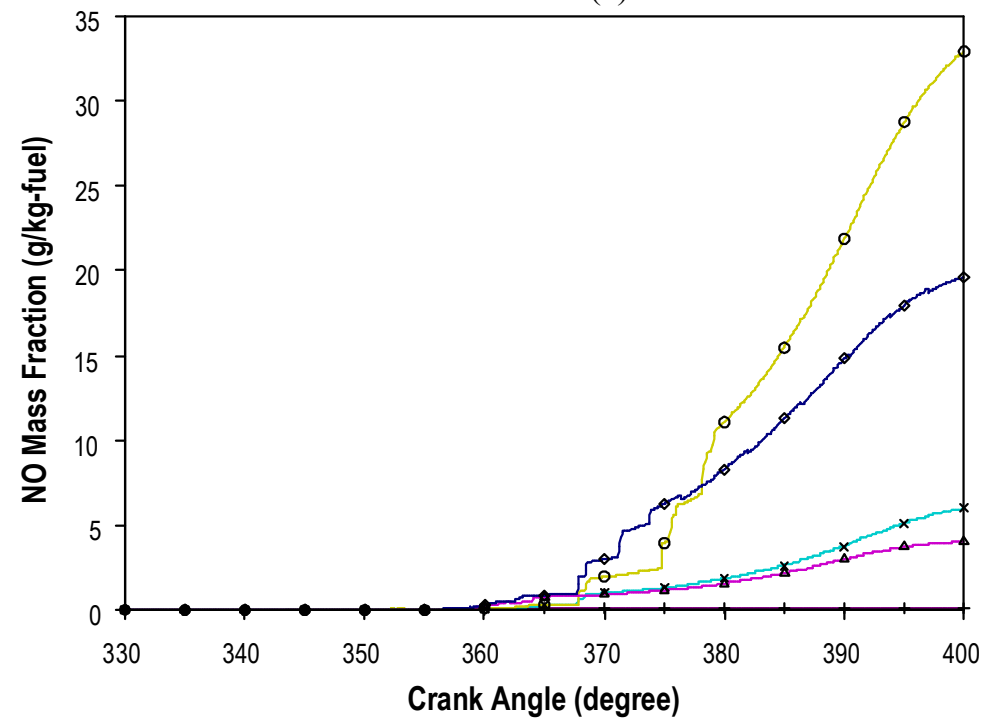

$\rightarrow$ DESIGN 1

$\triangle-D E S I G N 2$

- DESIGN 3

- DESIGN 4

+ DESIGN 5

(c)

Fig. 32. Predicted in-cylinder pressure, $\mathrm{CO}$ and $\mathrm{NO}$ emission using different start of injection timings. 
S. Abdullah et al. / JAFM, Vol. 1, No. 2, pp. 65-86, 2008.
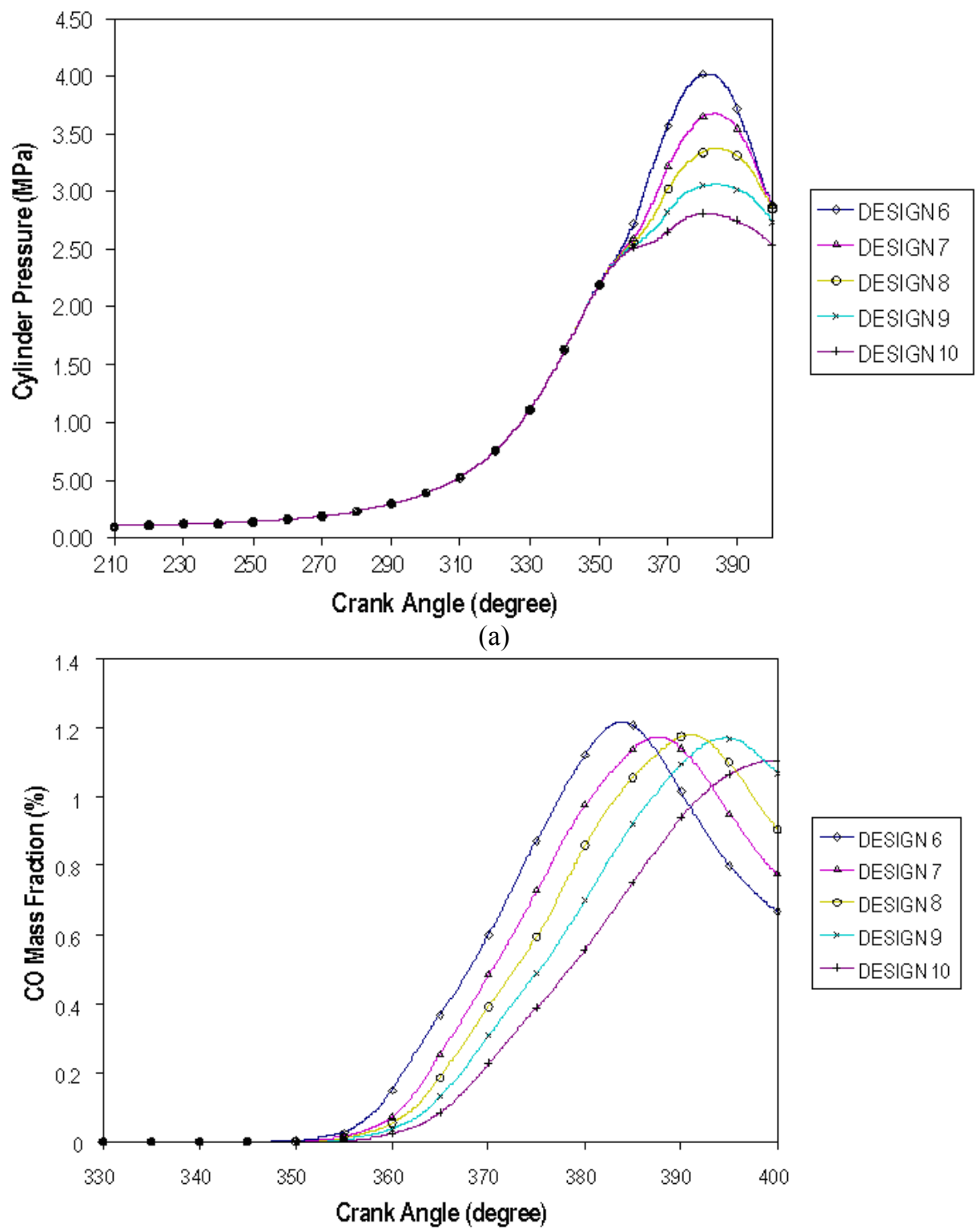

(b)

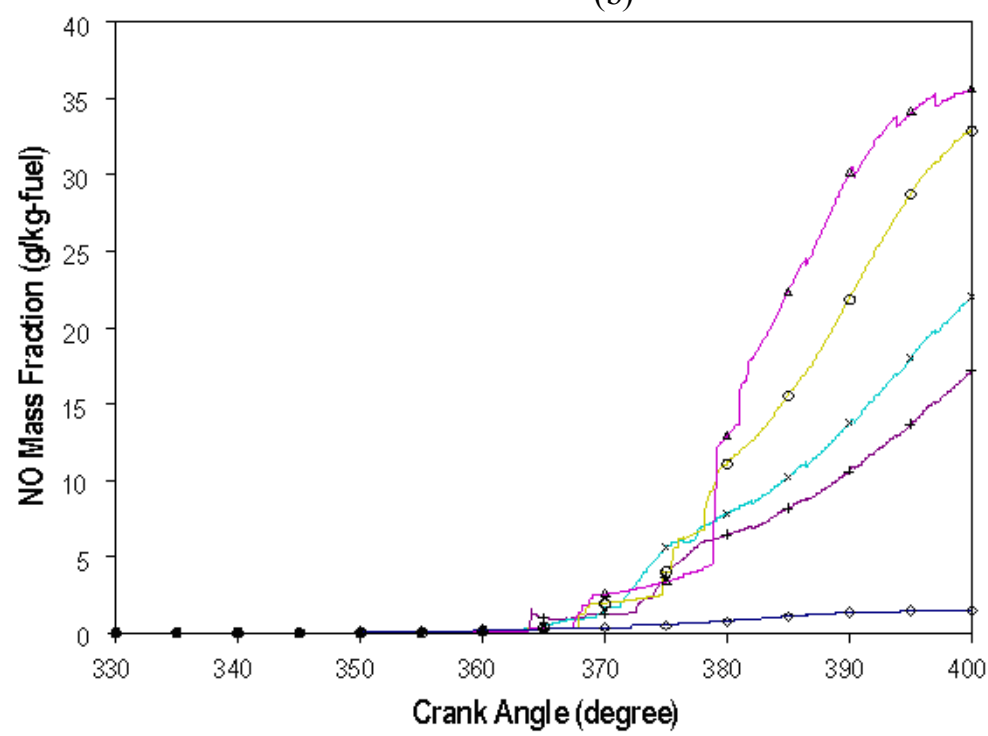

$\rightarrow-$ DESIGN 6
$\rightarrow-$ DESIGN7
- DESIGN 8
$\rightarrow-$ DESIGN 9
+ DESIGN 10

(c)

Fig. 33. Predicted in-cylinder pressure, $\mathrm{CO}$ and NO mass fraction using different ignition timings. 